\title{
THE ECONOMICS OF POPULATION an introduction
}

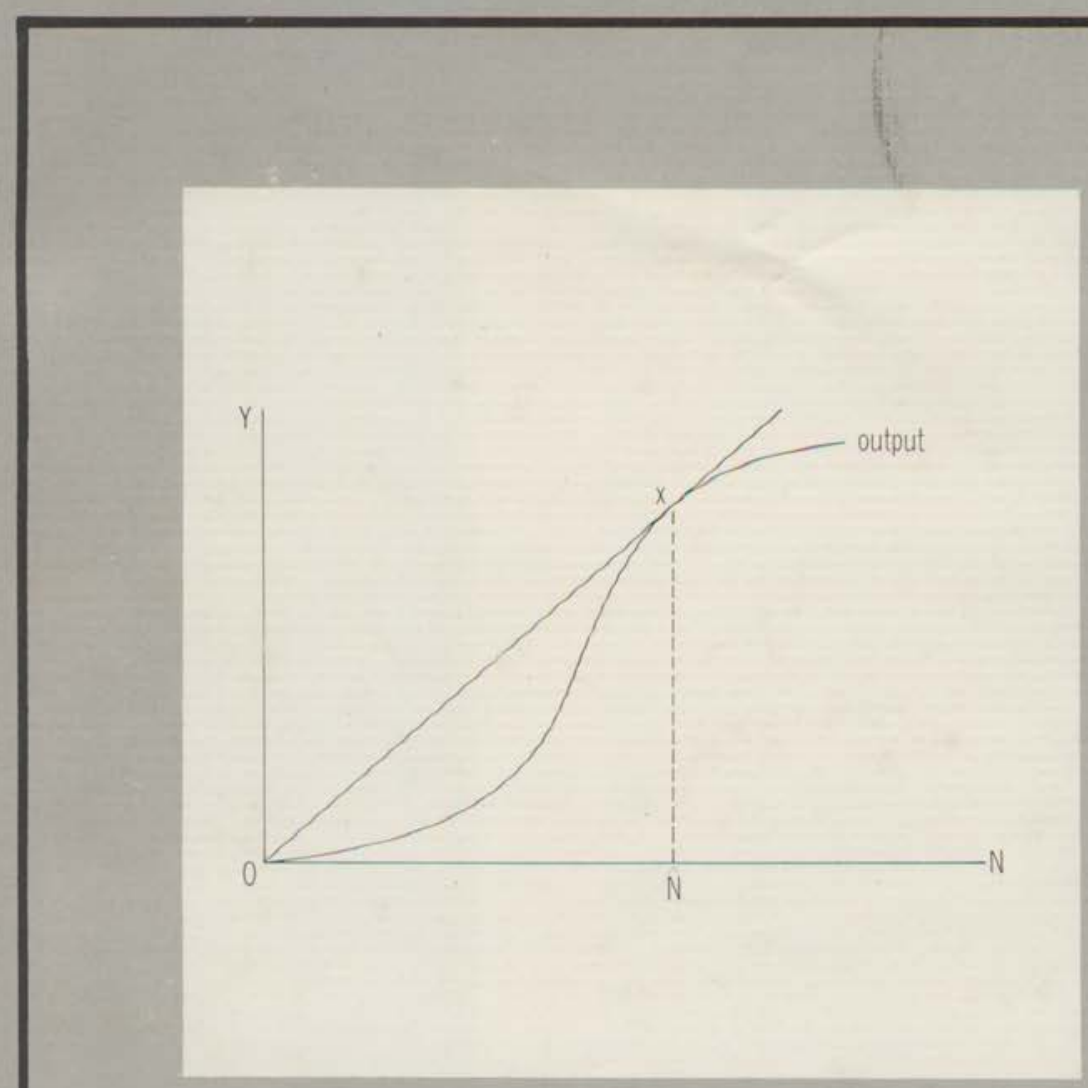

\section{J. D. PITCHFOR D}


The potentially explosive force of population growth poses questions to which the answers given by scientists of recent decades have often generated more heat than light. In this book we have an economist's approach to the problem. Professor Pitchford discusses the long-run relationships between a country's population and its economic development, exploring ways in which population policy can be directed towards improving economic welfare.

Assuming no specialised knowledge of economics, Professor Pitchford guides his reader lucidly through the concepts of production and employment to an important reformulation of the concept of optimum population. With the help of clear diagrams he introduces the various theories of population change and standard models of population processes before returning to optimum population and practical policies for attaining balanced states. Throughout, particular stress is laid on the place in economic theory of both renewable and exhaustible resources.

This is a book for students of economics, demography and ecology, for policy makers and for the growing body of people showing intelligent concern for the problems of an increasingly crowded planet. 
This book was published by ANU Press between 1965-1991.

This republication is part of the digitisation project being carried out by Scholarly Information Services/Library and ANU Press.

This project aims to make past scholarly works published by The Australian National University available to a global audience under its open-access policy. 


\section{J. D. PITCHFORD}

\section{The Economics}

of Population:

an Introduction

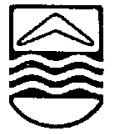

AUSTRALIAN

NATIONAL UNIVERSITY

PRESS CANBERRA 1974 
First published in Australia 1974

Printed in Australia for the Australian National University Press, Canberra

Southeast Asia: Angus \& Robertson (S.E. Asia) Pty Ltd, Singapore

Japan: United Publishers Services Ltd, Tokyo

O J. D. Pitchford 1974

This book is copyright. Apart from any fair dealing for the purposes of private study, research, criticism, or review, as permitted under the Copyright Act, no part may be reproduced by any process without written permission. Inquiries should be made to the publisher.

ISBN $070810570 \mathrm{X}$

Library of Congress Catalog Card no. 73-91823 


\section{Preface}

THERE is a growing interest in the relationship between a community's population and its standard of living. Although economists have contributed to the understanding of this subject, there is no readily available summary of their work, and it is therefore not surprising that non-economists are mostly unaware of these contributions. Moreover, there are gaps in the development of the topic, and there are aspects of the theory of economic growth which have been developed in such a way as to be positively misleading when attention is focused on the population variable. I have written this book to provide a summary and to add to existing contributions in the hope of filling some of the gaps. Because contributions to this subject are growing rapidly there are inevitably some works which I have been forced to neglect. In particular the recent papers on the economics of household decision-making by Becker, Nerlove and others seem to indicate a possible new approach to fertility questions. The March-April 1973 Journal of Political Economy is entirely devoted to articles on this subject. These authors attempt to find economic rationale behind household decisions, hence bringing decisions about family size into a relationship with economic variables. I have touched on some of Becker's earlier work in Chapter 3, but have not tried to incorporate recent developments. A survey of this material will be far more appropriate in a few years' time.

I have written this book at a level appropriate for undergraduate economics students, but it should also be accessible, and I hope of interest to others. One problem which I had to resolve was the 
extent to which I would use the convenience of mathematics to derive propositions. In fact, I decided to write the book on the assumption that the reader had almost no knowledge of mathematics. Looking through the following pages it will be noticed that a number of equations and diagrams are used, but mathematics is employed only as a form of shorthand. The reader who is daunted by mathematics can take comfort from the fact that a non-mathematician has read the book without difficulty.

To a large extent this book is based on a more technical treatment of this material entitled Population in Economic Growth, published by North-Holland. I am grateful for their permission to draw heavily on this earlier work. A version of the present work has been submitted to the Australian Population Enquiry under the title Aspects of the Economics of Population.

Betty Millington. Graham Tucker and Cliff Walsh read earlier drafts of the book and provided valuable comments. The diagrams were prepared by Pam Millwood of the Geography Department, Australian National University. I am grateful also to Sharon Kaspura for research assistance and Beryl Palmer for typing the manuscript.

J. D. PITCHFORD

Canberra

September 1973 


\section{Contents}

Preface v

1 Introduction 1

Outline 4

2 Production and Population 7

Production Theory $\quad 7$

Optimum Population 11

Growth Economics 18

3 Population Growth 23

The Standard Demographic Model 23

Arithmetical Theories $\quad 26$

Demographic Transition $\quad 27$

Ricardian Theory $\quad 28$

Fecundity and Fertility $\quad 30$

Empirical Testing of Net Fertility Theories 31

Population Growth in an Economic Context 34

4 Optimum Population 40

Alternative Criteria for Optimum Population $\quad 42$

The Many Goods Case $\quad 49$

International Trade 51

Resources $\quad 54$

Optimum Population and Resources $\quad 60$ 
Estimates of Optimum Population 65

Further Comments on the Stationary State 68

5 Paths to Optimum Population 72

Population Control 73

A Simple Model of Population Control . 76

Age-Structure and Population Control $\quad 82$

Exhaustible Resources $\quad 89$

Concluding Remarks $\quad 93$

$\begin{array}{ll}\text { Index } & 97\end{array}$ 


\section{Introduction}

WE shall be concerned to analyse the connection between a country's population level and trends and the well-being of its average citizen. It is useful to begin by looking at the dimensions of the population issue which confronts us today.

The main facts about the present state of world population are summarised in Table 1.1. In 1971 the total world population was 3706 million persons, and was growing at a rate of 2 per cent, with a birth rate of 34 per thousand and death rate of 14 per thousand. ${ }^{1}$ Over half of world population live in Asia, with a growth rate of 2.3 per cent and birth and death rates of 38 and 15 per thousand, respectively. By contrast, in Western Europe the growth rate was 0.7 per cent, with birth rate 17 and death rate 11 .

In India, for instance, over the last decade fertility has been virtually constant whilst mortality has declined, producing a marked increase in growth. Fertility has been high both because of almost universal marriage, and because the age of marriage is about seventeen years. The table illustrates that there is scope for further falls in Asian death rates and so further acceleration of population growth.

Africa, with just under 10 per cent of the world's population, has the highest birth and death rates of any of the major groupings. Again low age at marriage and almost universal marriage are common features of many African countries. The potential for further growth implicit in possible future falls in the death rate is considerable.

Latin America generally has achieved very low levels of mortality by world standards, but birth rates are similar to those in Asia,

${ }^{1}$ Birth, death and growth rates are calculated for the period 1965-71. 
TABLE $1 \cdot 1$

World Population Levels and Trends

\begin{tabular}{|c|c|c|c|c|c|}
\hline & $\begin{array}{l}\text { mid-year } \\
\text { popula- } \\
\text { tion } \\
\text { millions } \\
1971\end{array}$ & $\begin{array}{l}\text { annual } \\
\text { rate of } \\
\text { popula- } \\
\text { tion } \\
\text { increase } \\
\text { per cent } \\
1965-71\end{array}$ & $\begin{array}{c}\text { birth rate } \\
\quad / 1000 \\
1965-71\end{array}$ & $\begin{array}{l}\text { death rate } \\
\qquad / 1000\end{array}$ & $\begin{array}{l}\text { density } \\
\text { /sq. km. }\end{array}$ \\
\hline World Total & 3706 & $2 \cdot 0$ & 34 & 14 & 27 \\
\hline Africa & 354 & $2 \cdot 6$ & 47 & 21 & 12 \\
\hline North America & 230 & $1 \cdot 2$ & 18 & 9 & 11 \\
\hline Latin America: & 291 & $2 \cdot 9$ & 38 & 10 & 14 \\
\hline Tropical South & 155 & $3 \cdot 0$ & 40 & 10 & 11 \\
\hline Middle America & 70 & $3 \cdot 4$ & 43 & 10 & 28 \\
\hline Temperate South & 40 & $1 \cdot 8$ & 25 & 8 & 10 \\
\hline Caribbean & 26 & $2 \cdot 2$ & 35 & 11 & 111 \\
\hline Asia: & 2104 & $2 \cdot 3$ & 38 & 15 & 76 \\
\hline East & 946 & $1 \cdot 8$ & 31 & 14 & 80 \\
\hline South & 1158 & $2 \cdot 8$ & 44 & 17 & 73 \\
\hline Europe: & 466 & 0.8 & 17 & 10 & 94 \\
\hline West & 150 & 0.7 & 17 & 11 & 150 \\
\hline South & 130 & 0.9 & 19 & 9 & 99 \\
\hline East & 105 & $0 \cdot 8$ & 17 & 10 & 106 \\
\hline North & 81 & 0.6 & 17 & 11 & 50 \\
\hline Oceania: & $19 \cdot 8$ & $2 \cdot 0$ & 25 & 10 & 2 \\
\hline Australia and NZ & $15 \cdot 7$ & $1 \cdot 9$ & 21 & 9 & 2 \\
\hline USSR & 245 & $1 \cdot 0$ & 18 & 8 & 11 \\
\hline
\end{tabular}

Source: Demographic Yearbook, 1971, United Nations.

with the result that population grows at almost 3 per cent per annum. In urban areas fertility is at much lower levels than in rural areas, but the large proportion of rural dwellers ensures these high growth rates.

Europe, the USSR and North America present a vastly different demographic picture. Death rates are so low that further falls can have very little effect on the growth rate of population, and birth rates are correspondingly low, producing a typical growth rate of 
about 1 per cent. In the United States the net reproduction rate ${ }^{2}$ has recently fallen almost to unity, suggesting that, if it stays at that level, population will eventually stabilise. About one quarter of the world's population lives in these areas.

Even though the developed countries have a relatively low rate of growth of population their potential for future growth is still considerable. When a country whose population has been growing experiences a fall in fertility so that family size is just consistent with replacement, it will nevertheless be some time before population stops growing. The reason is that a growing population is relatively young and so has a disproportionate number of females in the reproductive age span as compared with a stable population. In many developed countries fertility is higher than consistent with replacement. By comparison the growth potential of populations in less developed areas is tremendous. The prospect of very rapid population growth in less developed countries, and of small but significant population growth in the high consumption, developed areas, would seem to pose some of the most important current problems in economics (and in many other fields) for the world today. In this book I have tried to set out a way of thinking about these issues.

Because the subject of population economics is a large one I have had to be selective. Problems relating to the level of unemployment, the rate of inflation, and to some extent the balance of payments are usually called short-run problems. This is not altogether an apt term because, for instance, unemployment, whilst it may be due to deficiency of demand which can quickly be corrected, may also arise from some structural problem which can be overcome only after long adjustment. Many interesting questions about population are associated with these short-run questions. Will immigration increase or reduce the rate of inflation? How does the birth rate vary over the trade cycle? None of these sorts of issue will be tackled here. Instead we shall be concerned to analyse the relationships between population and economic growth-the long-run issues. The reason for this choice is straightforward. Most changes in fertility, mortality, emigration or immigration take a very long time to work themselves out. Time lags in the process of population growth are introduced by age-structure, so that, for instance, a

${ }^{2}$ This concept is explained in the first section of Chapter 3 . 
decrease in births now will not itself affect fertility for at least fifteen years. Hence whilst population growth may have many short-run consequences its full effects are essentially a long-run question.

What are these long-run population issues? In what follows population is viewed as an integral part of the process of economic development and change. From this aspect it is often said that population levels are too high or too low and/or population growth rates are too high or low. The chief aim will be to formulate these questions sufficiently precisely so that it can be seen exactly what they involve. Hopefully this will suggest ways of attempting to answer them in practice. Non-economists often express impatience with this approach, for they feel that it should be possible to go immediately to the data and say what population or its growth rate 'should' be. A conclusion of this book is that if one wishes to take a community's preferences, productive capacity, and resources into account in a reasonable way, there is no possibility of such a simple procedure.

Most of the discussion, therefore, is centred on the economic and demographic tools needed to analyse the problem. In the main they are standard tools and few economists would disagree with their use. However, there is scope for disagreement about the way I have brought them to bear on the questions, so that it should not be thought that all the discussion involves received economic theory. An example of this is my use of the term optimum population. I have abandoned the classical notion of this concept, which, anyway, had been largely discredited by earlier writers, but have reinstated the term with reference to a concept which does seem to have operational value.

\section{OUTLINE}

The purpose of Chapter 2 is to explain some basic relationships between population and production. It is intentionally simple and devoid of too much detail so as to bring out clearly the nature of the economics involved. The central concept is that of a production function, a relationship between productive inputs and outputs of goods and services. Two exercises in the application of this concept are undertaken, and they illustrate quite opposite views of the role of population. One of them, the neoclassical growth model, is shown 
to imply that population may grow forever at a constant rate without output per head falling below an acceptable level. In the other exercise production conditions which seem more realistic (and which are inconsistent with perpetual population growth) are investigated. The production conditions examined are shown to imply the existence of an optimum population. This term is used, in Chapter 2, to refer to a state in which population and the stock of capital equipment are such that output per head is maximised. In order to understand what conditions must be satisfied so as to achieve this state, it is necessary to examine the notion of the economies (and diseconomies) of scale in production. The relationship between optimum population and the economies of scale is then explored.

Chapter 3 is devoted to population growth. The point of departure is a model of population growth which identifies the age-structure of the population and the relationships between age-groups. A common first approach of demographers is to take age-specific birth and death rates to be constant and to examine the consequent changes in the level, rate of growth and age-structure of the population. Whilst this reveals interesting and fundamental aspects of population growth it is clear that the evidence for most countries does not support the assumption of approximately fixed age-specific rates of mortality and, particularly, of fertility. Thus it is necessary to examine theories which directly or indirectly explain fertility and mortality changes. These I group under the headings: arithmetical theories, demographic transition, Ricardian theory and fertility and fecundity. To complete the discussion requires an examination of some of the work which has been directed at testing these theories.

The concluding section of the chapter discusses the Ricardian theory of economic development, which stresses the interaction between population growth and resources. It is shown that the implications of this analysis are that shortages of resources will (in the absence of continuing technical progress) lead to a stationary state with wages at subsistence level.

Chapter 4 elaborates and refines the concept of optimum population which was initially examined in Chapter 2 . Alternative concepts of optimum population are there introduced, and their implications are contrasted. For many economies optimum population must depend partly on their international trade experience, and a section 
is devoted to analysing how changes in this experience might affect the optimum. Next resources are examined, and a distinction is made between renewable and exhaustible resources. Discussion of the effects of the latter type is left to Chapter 5, but renewable resource effects are examined closely.

The question of what can be done to estimate optimum population is still an open one. This topic attracted considerable attention in Australia in the 1920s and 1930s, and various estimates which were made of Australia's desired future population are reviewed.

Finally, a section is devoted to some general comments on the nature of the stationary state which have not been included elsewhere.

Chapter 5 deals with the question of how, from any given position, an economy should move to a desired population level. It is assumed that fertility can be altered by appropriate expenditure, and the justifications for such interference in private decision-making are carefully examined. This question is approached by first formulating a simple model which ignores, amongst other things, the consequences arising from the age-structure of the population. However, it does suggest the types of criteria which should influence the path. The next model incorporates age-structure and is, of necessity, more detailed and complex. It does seem to cover some of the main sources of costs and benefits from fertility control expenditures. Lastly, exhaustible resources are introduced, and it is then shown how an optimum population state based on the exploitation of such resources can be defined. Of course, such a state cannot last indefinitely, and a transition to an economic organisation without such resources, and consequently with a lower per capita output, is inevitable.

As with all economic theory the aim of these chapters is to direct attention towards relevant issues, and to suggest what questions need to be examined empirically. Such empirical examinations will not be easy, but there is an increasing necessity for them to be tried. 


\section{Production and Population}

To begin with I have tried to give a simple account of the essence of production theory and to provide applications which will illustrate its use in the context of population questions. Readers familiar with the way in which production is handled in economic analysis may wish to omit the first section of the chapter. Those unfamiliar with this material are advised to study the chapter carefully, for it forms an indispensable background to the economist's approach to population questions.

\section{PRODUCTION THEORY}

In order to describe and make judgments about the economics of population growth, it would seem that a set of concepts relating to the way in which goods are produced is essential. This set of concepts will be called a theory of production, and it is not hard to see why it is needed. From the total population a certain number of individuals (the work force) will be available to produce goods in conjunction with inputs of materials and the services of capital equipment, and all of the population will be consumers of these goods. Population and production thus have a two way relationship, and it is the investigation of this interdependence which is the subject of this work, and which distinguishes the economist from the demographer, for the latter does not usually concentrate on the links between population and production.

Having established a need to study production theory, it must be recognised that productive processes are not usually amenable to simple analysis. This rather unfortunate state of affairs is at the root 
of many controversies in economics. What economists are forced to do is to try to simplify real phenomena so that they are capable of manipulation to produce testable hypotheses, whilst still preserving their essential features. It should also be observed that some of the simplifying assumptions made are for the quite different purposes firstly of avoiding the lack of communication resulting from mathematical reasoning, and secondly of eliminating from the theory irrelevant features, which would distract attention from the main points without contributing substantially to our understanding.

Consider first a single firm producing a single output, whose quantity will be denoted by the symbol Y. (Mathematical symbols will be used to obtain shorthand expressions, not for manipulation.) The firm produces output by transforming inputs of materials (M), the services of labour $(\mathrm{N})$ and capital equipment $(\mathrm{K})$ into the desired form. This process may be represented symbolically by $(2 \cdot 1) \quad \mathrm{Y}=\phi(\mathrm{M}, \mathrm{N}, \mathrm{K})$

which should be read as stating that the quantity of output produced in a given period of time depends upon the inputs of the services of $\mathrm{N}$ and $\mathrm{K}$, together with materials used (M) in that time period. The relationship implied by $(2 \cdot 1)$ is called a production function. The symbol $\phi$ combines two roles. When it follows an equals sign it may be read simply as 'depends on'. Sometimes, however, it is useful to have a symbol for output which emphasises the things on which it depends. For instance $\phi(\mathrm{M}, \mathrm{N}, \mathrm{K})$ can be read as 'output, depending on inputs of materials, labour services, and capital services'. When $\phi$ does not follow an equality sign it is an alternative symbol for output, and on its own $\phi$ is taken to mean 'output which depends on the determinants specified'.

The dependence of output on inputs is not as simple as it may seem, for at least two reasons. Firstly, the relationship may change through time owing to technical improvements in capital equipment, in the organisation of production, and in the skill of the labour force. All these matters will be lumped together under the heading of technical progress, and unless otherwise noted, the problem will be simplified by abstracting from such technical change. Secondly, capital equipment depreciates through use and the elapse of time and replacement is necessary to maintain the stock of equipment.

Associated with the dependence of output on inputs are two 
measures which relate to an inputs efficiency. These may be illustrated with respect to labour. The average product of labour is simply the ratio of output to labour input $\left(\frac{\mathrm{Y}}{\mathrm{N}}\right)$. Alternatively, it is called output per head. This ratio, of course, reflects not only the skill of the labour force but most importantly the quantity of cooperative factors with which labour is working, and whether largescale production methods are in operation. A heavily capitalised firm could be expected to produce with a high average product of labour. The second measure is called the marginal product of labour $\left(Y_{N}\right)$. Its value lies in the fact that it captures some of the consequences of changes in inputs. To help understand this concept suppose that the labour input was increased by one worker per period, all other inputs being at constant levels, then the marginal product of labour measures the resulting increase in output. At the one extreme a productive plant may be so structured that it may not be able to absorb an extra worker without increasing other inputs. Then the marginal product of labour is zero. Another extreme and also unlikely case is that labour is the only input, so that all the additional product can be said to be labour's marginal product. Both these measures (average and marginal product) play a crucial part in the theory of optimum population, as will be shown.

Another concept which also helps to classify features of a productive system is the notion of returns to scale. Assume that all the inputs are increased in the same proportion; to help fix ideas it will suffice to assume they are doubled. If output also doubles it is said that the firm is operating under conditions of constant returns to scale. There is a sense in which constant scale returns are a natural outcome, for if one exactly duplicates a plant and feeds the new plant with inputs in the same amounts as the old then its output will be the same as before, and total output doubles. Yet this idealised outcome is unlikely to be met with universally for, in duplicating inputs of material and/or labour, it may well be found that inferior inputs only are available so that output does not double. In such circumstances, when output less than doubles it is said that there are decreasing returns to scale.

On the other hand, to duplicate a piece of capital equipment may not be the most efficient way of doubling capital. A better way may be to use a plant specially designed for the doubled inputs of mater- 
ials and labour, and so find that it is possible more than to double output. In such a case it is said that there are economies of largescale production, or increasing returns to scale.

So far the discussion has related to a single firm, but to deal with population issues it is necessary to take an economy-wide view of production. An analysis which involves a large number of firms is capable of being manipulated to produce results, but often at a considerable cost in terms of complexity. What alternative is there? For the economy as a whole there is a simple device which enables us to talk as if there were only one good being produced, although there is some loss of generality in this procedure. Adopting the fiction that all goods are produced and consumed in fixed proportions, then it follows that the economy must act as if it were producing a single good (with a multitude of physical aspects). By this assumption, problems of the changing composition of output are ignored, but it is arguable that these are not of the first order of importance for population economics. Anyway, we shall show in Chapter 4 how to handle the problem when a variety of commodities not produced in fixed proportions is allowed for. The production function $(2 \cdot 1)$ now may be thought of as referring to total or aggregate output for the economy, where $\mathrm{M}, \mathrm{N}$, and $\mathrm{K}$ are the aggregate inputs for the economy. The input $\mathrm{N}$ will now measure the total work force, which will fall short of population as some individuals will, of course, not be available to work. For the present chapter, however, it is simplest to assume that all the population works and so to use the terms work force and population interchangeably.

The next, and last step before putting the notions to work concerns the treatment of materials. Such inputs can be thought of as a flow of services from the environment, and this notion has been given prominence in economic analysis at least since the writings of Malthus and Ricardo in the early 1800 s under the general description land. Now land (L) is a stock whilst materials have been treated as a flow (per unit time), but as long as this is remembered there is no harm in writing $(2 \cdot 1)$ as

$$
\mathrm{Y}=\phi(\mathrm{L}, \mathrm{N}, \mathrm{K})
$$

from which we read that output depends on the inputs of services 
from the classic trilogy: land, labour and capital. The step now to be made is to drop land from $(2 \cdot 2)$, so writing

$$
\mathrm{Y}=\phi(\mathrm{N}, \mathrm{K})
$$

This seems to neglect the services of land, and in many but not all respects this is the case. There are two polar cases in which $(2 \cdot 3)$ may still be thought of as including land, and they reflect interesting divergences of approach to the environment which will appear in the applications which follow.

In the first case land (which is, remember, a shorthand term for all resources) is taken to be so plentiful relative to present demands that it is essentially a free factor. It is only the fact that labour and capital must be used to transform its services to an appropriate form which gives value to output, and prevents us being able to satisfy all our needs. Much land is idle, and this idle land is in quality essentially not inferior to that in use.

At the other extreme all suitable land is in use, so that the quantity of output can be expanded only by using land more intensively, that is, with more capital and/or labour. Here land is said to be a fixed factor.

We have so far been neglecting the possibilities raised by international trade. Such trade widens the scope of a country's purchases beyond that of its domestic production, and widens the market for its production beyond that of domestic consumers. It may thus be of considerable importance in questions of population policy, but because of the complications it raises, consideration of its effects is postponed until Chapter 4 . We shall proceed on the assumption that our economy does not engage in international trade, so that it may be called a closed economy.

Now it is possible to put these concepts into operation so as to see what conclusion they yield when brought to bear on specific topics. It must be recognised that something of reality has been lost in all these definitions, yet a structure is available in which the essence of many problems can be preserved. Moreover, debate about precisely what some term means should have been largely overcome.

\section{OPTIMUM POPULATION}

Take first the problem of optimum population. Some countries, it is often argued, should support a larger population than they 
already have, whilst other countries are said to be overpopulated. Such statements as these seem to be referring to a desirable level or range of population, in comparison with which present population is too small or large. How are such judgments to be given precise content; that is, what determines optimum population for a given area? To make a judgment about desirability a criterion is needed to distinguish whether one situation is better than another. It is not the right of the economist to provide the criterion. Ideally it will emerge from some sort of political process which reflects voters' opinions. However, it is not unreasonable to anticipate that whatever criterion is chosen will probably depend heavily on consumption per head. With higher per capita consumption a community can have more private goods such as food, clothing, leisure, and more public goods such as hospitals, schools, roads, parks for each individual. By itself, this is the simplest and probably the most generally acceptable guide to community welfare.

What is being discussed now is a desirable population level. Optimum population may be defined as that stationary population level which when appropriately supplied with capital equipment (such as factories, roads, bridges, etc.) results in the maximum consumption per head of population, whilst maintaining a constant quality and supply of renewable resources (and exploiting exhaustible resources at an appropriate rate). In thinking of consumer goods we often envisage such things as cars, refrigerators, foodstuffs, etc., but of course there is no reason why this term should not include nonmaterial goods such as education, and environmental goods such as clean air, national parks and so on. However, for purposes of simplification I shall concentrate in this chapter on the sorts of goods usually treated as consumption in the national income accounts. As a first approach to this complex problem suppose that the supply of available land is $\mathrm{L}$ so that the employment of land may be less than or equal to $\bar{L}$. Up to $\mathrm{L}$ land may be treated as a free factor, but when $\mathrm{L}$ is reached it becomes a fixed factor. Capital is assumed to be 'appropriately' chosen, but what exactly this implies will only become clear later. For shorthand purposes, and so as to achieve precision we may write our problem

$$
\underset{L, N, K}{\operatorname{Max} .(c), \quad L \leqslant L}
$$


Now consumption per head (c) will be closely related to the average productivity of labour (or output per head). In a stationary economy the two main demands on output are for consumer goods, and to renew capital equipment which is depreciating. We shall take it that the output measure which we have defined is net of replacement to make good this depreciation. Hence net output is all available for consumption, so that $\frac{\mathrm{Y}}{\mathrm{N}}=\mathrm{c}$. Thus we seek to find $\mathrm{L}, \mathrm{N}$, and $\mathrm{K}$ to maximise output per head, that is we wish to

$$
\underset{\mathrm{L}, \mathrm{N}, \mathrm{K}}{\mathrm{Max}}\left(\frac{\phi(\mathrm{N}, \mathrm{L}, \mathrm{K})}{\mathrm{N}}\right), \mathrm{L} \leq \mathrm{L}
$$

The solution to this problem will take the form of an optimum input combination $(\hat{\mathrm{N}}, \hat{\mathrm{R}}, \hat{\mathrm{L}})$ which gives rise to a maximum level of consumption per head $(\hat{c})$. (The $\wedge$ notation will be used in future to denote optimum values of variables.)

Consider first the case of constant returns to scale and assume that we have found the $c$ that solves the problem. It can be shown that our production function may be depicted as in Figure 2.1. To see this note that $\frac{\mathrm{Y}}{\mathrm{N}}=\hat{\mathrm{c}}$ at the optimum point, so that $\mathrm{Y}=\hat{\mathrm{cN}}$.

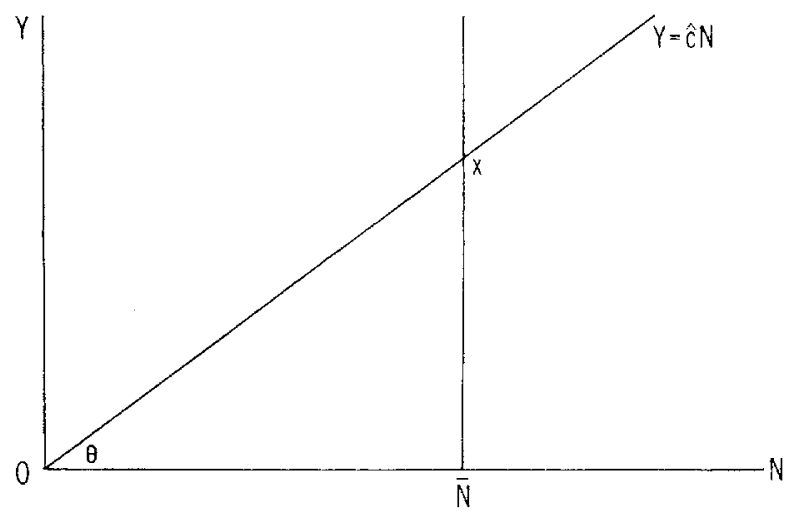

Figure $2 \cdot 1$

Now halve all inputs, and because of constant returns to scale output is also halved, so that for each value of $\mathrm{N}$ (with corresponding $\mathrm{L}$ and $\mathrm{K}) \mathrm{Y}=\hat{\mathrm{c}} \mathrm{N}$. Thus the straight line passing through the origin with slope $\hat{c}$ depicts solutions to the problem. But this has strange 
consequences. Suppose when $\mathrm{N}=\overline{\mathrm{N}}$ we have used up all land, that is, $\mathrm{L}=\mathrm{L}$. Any population level at all between zero and $\overline{\mathrm{N}}$ can be optimal provided it is appropriately supplied with land and capital! With constant returns to scale the criterion of maximising consumption per head is not sufficient to enable choice of an optimum population. If the world were really like this some further considerations such as desired density of settlement must be introduced before a figure for optimum population can be specified.

However, we have argued that it is unlikely that the world is like this. In fact it was suggested that there will be increasing returns to scale at low levels of activity, and decreasing returns at high levels. To help illustrate this note that in Figure $2 \cdot 1$ output per head is $x \bar{N}$ divided by $O \bar{N}$, and so is directly related to the size of the angle $\theta$. Now Figure $2 \cdot 2$ is drawn so that output per head first rises and then

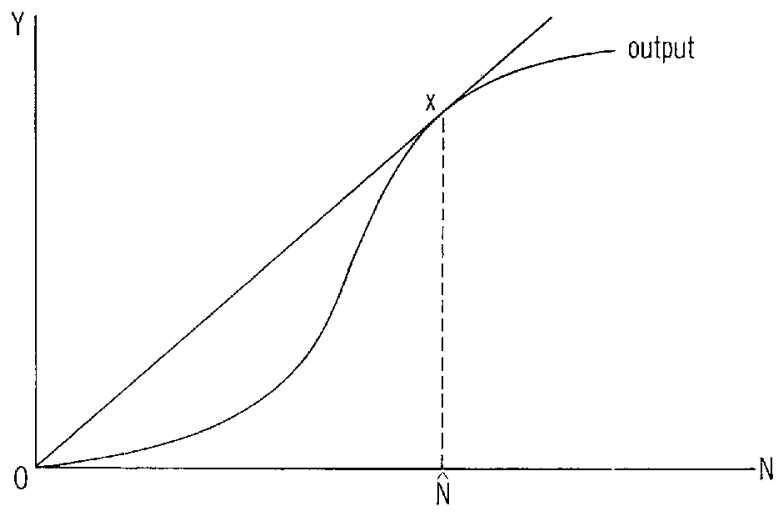

Figure $2 \cdot 2$

falls as population rises. (This may be checked by drawing a line from the origin to the output curve and observing that the angle $\theta$ first rises and then falls as $\mathrm{N}$ increases). Output per head is at a maximum at $\hat{\mathrm{N}}$, and this is then the unique optimum population level.

Assume that as we increase $\mathrm{N}$ we increase the supplies of other factors in the same proportion. Now because output per head rises in the phase up to $\hat{\mathrm{N}}$, output is rising faster than inputs so that it is a phase of increasing returns to scale. After $\hat{\mathrm{N}}$ output per head falls so that expanding inputs together by say 1 per cent results in a less 
than 1 per cent increase in output. Here we have decreasing returns to scale. Thus it can be seen that optimum population occurs at the point at which increasing returns to scale are just exhausted. This, after all, is no more than common sense. When we are talking about population we are talking about the size or scale of the economy. When we consider the economics of population levels we are asking such questions as: what scale will make the economy's living standards highest? We have come to a tentative conclusion that this scale is reached when economies of scale are just used up. This can be only a tentative conclusion for complications such as international trade and the changing composition of output remain to be considered in later chapters. Further, although reasons have been given suggesting that Figure $2 \cdot 1$ is inappropriate it should be noted that a situation such as that in Figure $2 \cdot 3$ is not inconceivable. After a phase of increasing returns to scale, there is a zone of constant returns in which any population level between $\hat{\mathrm{N}}_{1}$ and $\hat{\mathrm{N}}_{2}$ is optimal.

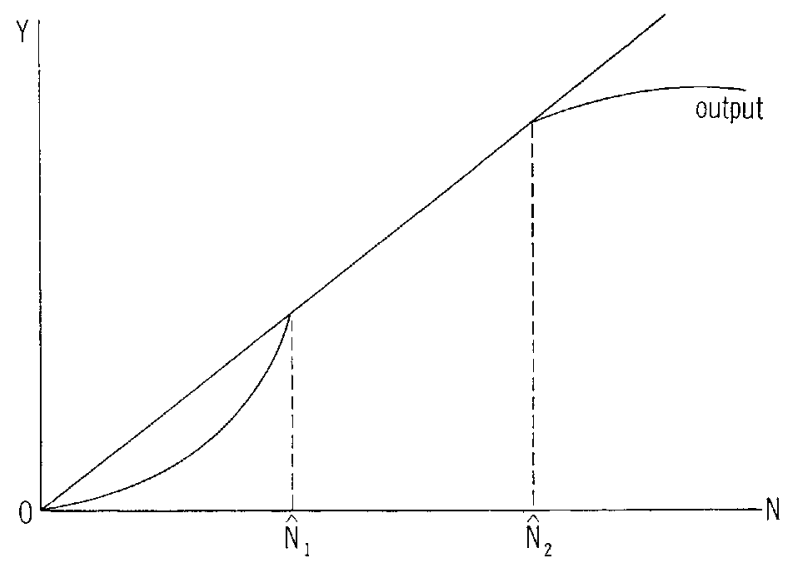

Figure $2 \cdot 3$

It is instructive to pursue the conditions for optimum population somewhat further. To do this it helps to identify the marginal product concept graphically. Figure $2 \cdot 4$ is drawn with capital and land held constant. If we imagine an increase in employment from $N_{1}$ to $N_{2}$, output will rise from $Y_{1}$ to $Y_{2}$. The marginal product is thus $Y_{2}-Y_{1}$ when labour increases by $N_{2}-N_{1}$ units, or 


$$
\frac{Y_{2}-Y_{1}}{N_{2}-N_{1}}
$$

when labour increases by one unit. Now the tangent to the output

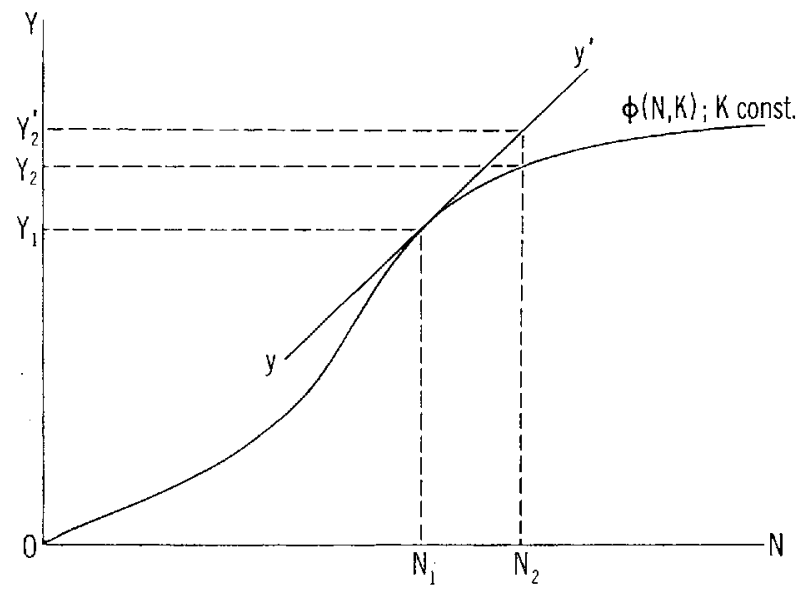

Figure 2:4

curve at $N_{1}$ is $y y^{\prime}$. Notice that the slope of this tangent is measured by $\frac{\mathrm{Y}_{2}^{\prime}-\mathrm{Y}_{1}}{\mathrm{~N}_{2}-\mathrm{N}_{1}}$. As the increment of labour $\left(\mathrm{N}_{2}-\mathrm{N}_{1}\right)$ gets smaller it can be seen that the marginal product $\frac{Y_{2}-Y_{1}}{N_{2}-N_{1}}$ gets closer and closer to the slope of the tangent. Indeed, by making $N_{2}-N_{1}$ sufficiently small, the marginal product as defined above can be made as close as desired to the slope of the tangent $y^{\prime}$. Hence it is logical to say that the slope of $y^{\prime}$ is the marginal product of labour at $N_{1}$. Now consider Figure $2 \cdot 2$ again (assuming now that $\mathrm{K}$ is constant). Optimum population occurs when the average product $x \hat{N} / O \hat{N}$ is equated to the marginal product of labour (given by the slope of the tangent at $\mathrm{x}$ ). Thus we may write one condition for optimum population as

(2.4) $\quad Y_{N}=\frac{Y}{N}$

The issues associated with maximising an average can be illustrated with reference to those related to a sportsman's average performance -the 'batting average' problem. A batsman's marginal score is 
given by his latest performance. He will raise his average score if his latest score is above the average, and will lower it if it is below. Hence he can continue to raise his average by marginal scores above the average. So it is seen that the average product of an economy rises if the produce of an additional unit of labour (marginal product) exceeds the average product. Hence it pays to keep increasing the labour force until the marginal product equals the average product. (If it were found that the marginal product fell short of the average product it would pay to reduce the labour force.) Thus we verify the rationale behind the result in $(2 \cdot 4)$.

This result has been obtained with $\mathrm{K}$ held constant. It holds whatever the constant value chosen so, in particular, it holds also when $\mathrm{K}$ is at its optimal level. In a similar manner let us hold $\mathrm{N}$ constant and investigate the condition associated with an optimum capital stock. This condition together with $(2 \cdot 4)$ will jointly determine both an optimal population and an optimal capital stock towards which an economy may wish to move. If $\mathrm{N}$ is given, changes in $\mathrm{K}$ can affect only output. Output will be increased by additional capital so long as the marginal product of capital $\left(\mathrm{Y}_{\mathrm{K}}\right)$ is positive. This is essentially no more than a consequence of the definition of capital's marginal product. Increasing $\mathrm{K}$ with $\mathrm{N}$ (and $\mathrm{L}$ ) unchanged raises $Y$ and hence $\frac{Y}{N}$ provided $Y_{K}$ is positive. Only at the point at which $Y_{K}$ is zero will it not pay to increase capital, so that the optimal capital condition becomes

(2.5) $\quad \mathrm{Y}_{\mathrm{K}}=0$

Figure $2 \cdot 5$ shows the determination of $\mathrm{R}$ at the point at which the tangent to the output line is horizontal.

We have noted that the appropriate output concept should be net of depreciation replacement. The more capital we have for production purposes the more there is to wear out. Hence it is the marginal product of capital net of additional depreciation which is the relevant concept here.

The usefulness of conditions $(2 \cdot 4)$ and $(2 \cdot 5)$ will become apparent when we develop the concept of optimum population further in Chapter 4. Together they may be shown to imply that returns to scale are just exhausted, but this derivation will not be attempted here. 


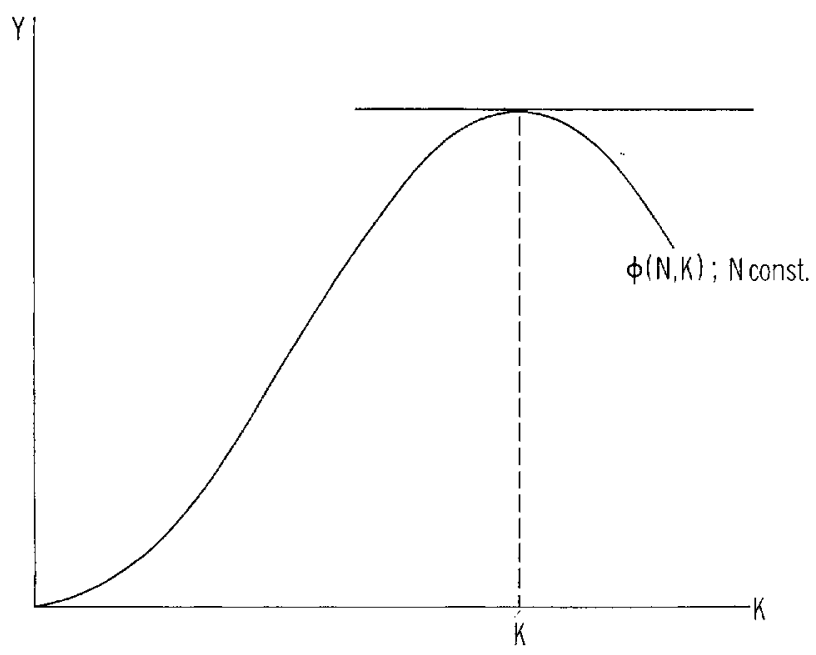

Figure $2 \cdot 5$

\section{GROWTH ECONOMICS}

To appreciate growth processes definitions are needed of various notions of the growth rate of a variable. This term is used to refer either to the absolute rate of growth or the percentage or proportional rate of growth and it is usually clear from the context which is meant. The absolute rate of growth is simply the absolute increase in a variable in a unit time period, whilst the proportional rate of growth is the ratio of its absolute increase to its value at the start of the period. A variable with a constant absolute rate of growth follows a linear trend, whilst constant proportional growth involves an exponential trend (see Figure $2 \cdot 6$ ).
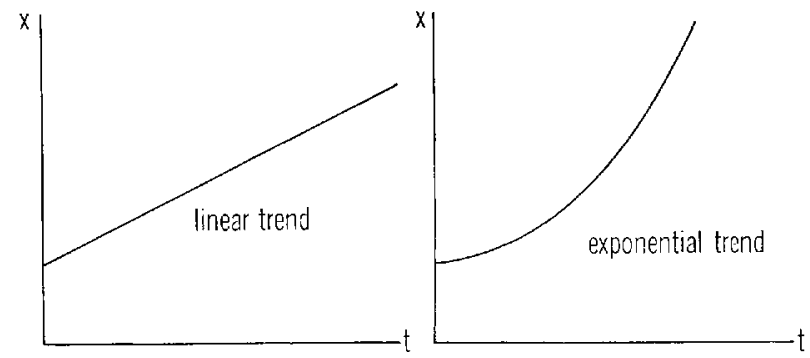

Figure $2 \cdot 6$ 
In the second half of the 1950s a number of economists proposed analyses of growth for an economy without unemployment. ${ }^{1}$ The work of Keynes had given governments ways of controlling unemployment, so that economists could return to the old problem of growth in a fully employed system. When Malthus and Ricardo had investigated this problem they had placed considerable importance on land as a limiting factor to growth. The vast increases in production during World War II and post-war reconstruction, and the growth orientation of much public thinking, made it natural for the 1950s growth models to be cast in a framework in which land was essentially a free good. Moreover, for an analysis in which the horizon is not too long this is not a bad assumption, especially if the purpose is to elucidate the relationship between capital accumulation and population growth. It is when a long-term view is taken that these models seem misleading.

I shall give a brief review of the growth model worked out by Swan in 1956. Output is determined by labour and capital inputs as given in (2.3), and is subject to constant returns to scale. To complete the system it is necessary to be able to say what determines the growth of labour and capital. For labour the assumption made was simple, and not too far removed from the facts. The proportional rate of growth of population was taken to be positive and constant.

In a fully employed economy capital growth is limited to the amount of income left after consumption demands have been met. This magnitude is called saving (S) and measures the difference between total income (equals total value of production $(\mathrm{Y}))^{2}$ and total spending on consumer goods. There is statistical evidence to suggest that, in the United States and other countries, when fluctuations are averaged out, saving is a constant proportion of income. Call this proportion $\mathrm{s}$, then absolute capital growth is $\mathrm{sY}$ and proportional capital growth is $\frac{s Y}{\mathrm{~K}}$.

It is useful to depict the growth rate of these two inputs graphically. In Figure $2 \cdot 7$ proportional growth rates are plotted on the vertical axis, and the ratio of output to capital is shown on the horizontal

${ }^{1}$ The works of Robinson (1956), Solow (1956) and Swan (1956) are the most important of these.

${ }_{2}$ The value of output will be distributed to various inputs, in the form of wages, salaries, rents and profit. Hence the value of output is equal to the value of ali incomes for the community. 
axis. Although Figure $2 \cdot 7$ will be used to suggest growth over time, it should be noted that time is not explicitly represented on either axis. This may seem confusing, but it must be remembered that, because growth rates are depicted, change over time will be taking place. Hence we shall see that a movement through time emerges in the diagram, and that it appears as a change in the relationships between different variables.

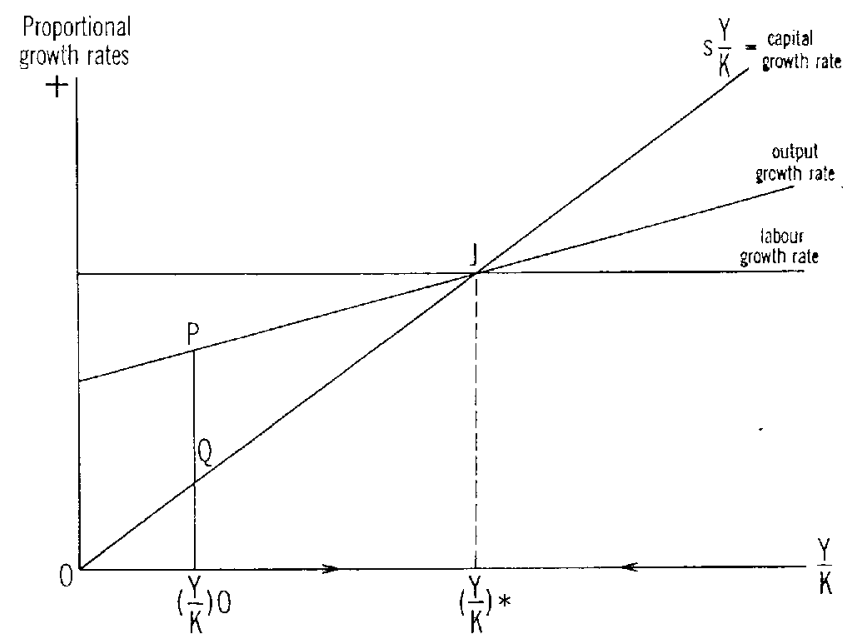

Figure $2 \cdot 7$

For labour the growth rate is constant irrespective of $\frac{Y}{K}$, and so is represented by a horizontal straight line. The capital growth line starts at the origin and is positively sloped (with slope s) and intersects the labour growth line when $\frac{\mathrm{Y}}{\mathrm{K}}=\left(\frac{\mathrm{Y}}{\mathrm{K}}\right)^{*}$. Where will the output growth line lie in relation to these input growth lines? The clue to this is given by the assumption of constant returns to scale. With such an assumption, if both inputs grow at the same rate, output also grows at the same rate. Hence the output growth line passes through the point $\mathrm{J}$. At other points one input is growing more rapidly than the other. Now with constant returns, output must grow faster than the slower growing factor, and slower than the faster growing factor. For example, if population grows at 1 per 
cent per annum and capital at 2 per cent per annum output will grow less fast than 2 per cent, but faster than 1 per cent per annum. It must follow that the output growth line at points other than $\left(\frac{\mathrm{Y}}{\mathrm{K}}\right)^{*}$ must be between the capital and the labour growth lines, as shown in Figure $2 \cdot 7 .^{3}$

Now it is possible to see how the system will grow. At some initial point of time the economy will possess a particular capital stock $\left(\mathrm{K}_{0}\right)$, and labour force $\left(\mathrm{N}_{0}\right)$ and so will produce a particular output $\left(\mathrm{Y}_{0}\right)$. Thus it will have at that time an initial output-capital ratio $\left(\frac{\mathrm{Y}}{\mathrm{K}}\right)_{0}$, and from Figure 2.7 it can be seen that output will grow at a rate measured by $O P$ and capital at a rate measured by $O Q$. Output grows faster than capital so that the ratio $\frac{\mathrm{Y}}{\mathrm{K}}$ must rise over time and will continue to rise towards the equilibrium point $\left(\frac{\mathrm{Y}}{\mathrm{K}}\right)$.* The economy is thus seen to move from any initial position towards a state in which both inputs and outputs are all growing at the same rate, which is the rate of growth of population. Such a situation may be called a moving equilibrium.

What happens if the economy saves more? If $\mathrm{s}$ rises to $\mathrm{s}^{\prime}$, when the economy is in its moving equilibrium at $\left(\frac{\mathrm{Y}}{\mathrm{K}}\right)^{*}$, it is easy to see that for a while the growth rate of output will be faster than before the rise. Eventually, however, the growth rate settles back to the same level as population growth. The reader could draw a second set of capital and output growth lines in Figure $2 \cdot 7$ to verify these propositions. Nevertheless it can be shown that in the new equilibrium the production process will be more capital intensive $\left(\left(\frac{\mathrm{Y}}{\mathrm{K}}\right)^{*}\right.$ will be lower) and output per head will be higher. This latter result is achieved because, in the transition, output will have grown faster than labour, resulting in a permanently higher average product of labour.

The two examples studied represent different types of approach to economic growth problems. The optimum population question

In Figure $2 \cdot 7$ the output growth line is drawn as a straight line. This would be the case if the production relationship is of the so-called Cobb-Douglas form. 
is a sample of the social optimising approach whereas the growth model is meant to be descriptive only of economic events. There is no reason why the descriptive model cannot be used as a framework for treating questions involving social optimality. Thus there is a considerable literature on the question of what path the system would take if the saving ratio s could be varied by fiscal and other methods according to some social criterion.

The two examples are further apart when their implications about economic events are studied. For the optimal population case it was seen that stationary population and capital levels solved the problem, but for the descriptive growth model it moved towards a state in which constant proportional expansion occurred. Yet it must be remembered that land in this expanding model was taken to be a free good. Sooner or later the limitations of the environment will ensure that the growth process must be modified and eventually cease altogether. The sorts of consideration involved in the study of optimum population are relevant even for those who believe that the nature of current growth is depicted by the Swan-type model.

\section{REFERENCES}

Robinson, J. R. 1956. The Accumulation of Capital, Macmillan, London. Solow, R. M. 1956. 'A Contribution to the Theory of Economic Growth', Quarterly Journal of Economics.

Swan, T. W. 1956. 'Economic Growth and Capital Accumulation', Economic Record. 


\section{Population Growth}

AT the beginning of the previous chapter it was remarked that economists are interested in population changes because these influence the numbers of producers and consumers. There are many and varied propositions about the ways in which populations change over time, and some of these will be reviewed in the present chapter. Certain theories are intended by their authors to be tested against reality, whilst other notions have different purposes. Thus, for instance, the framework which I have called the standard demographic model is not intended to be a proposition about how population will actually behave, but nevertheless contributes greatly to an understanding of the process of population growth.

After reviewing theories of population growth, a model involving interaction of population and economic conditions is presented.

\section{THE STANDARD DEMOGRAPHIC MODEL}

Consider a closed population. This is one which is not subject to emigration or immigration. Suppose also that in this closed population we consider only the females. The justification for doing this is that births depend largely on the number of females (but clearly in some cases a shortage or an excess of males will have a marked effect on the birth rate). One characteristic of the population (of females) is the age-structure which is a tabulation of the numbers in all age-groups, which for concreteness I shall assume is taken over five-year intervals from age zero to a maximum figure. Consider 1000 persons born at a particular time. Five years later suppose 900 of these are alive, then the mortality rate specific to the 0-4 age-group is 10 per cent. From such mortality rates (or the closely related concept of age-specific death rates) it is possible to project population 
forward provided these rates are assumed to stay constant. At a given time the numbers aged $0-4$ who survive five years to the age group 5-9 can be calculated from this assumption, and indeed we can similarly trace them through the total life span.

The model is completed when the number of births occurring in any five-year period can be explained. The main childbearing ages are $15-44$, so that the number of women at these ages is important as a determinant of births. The birth rate specific to the $20-24$ agegroup is the ratio of births during a five-year period to women in this group to the number in the group at the beginning of the period. If age-specific birth rates are assumed to be constant, then a complete explanation of births will be given once the age-structure of the population is known.

A self-contained system has now been established. Given an initial population it will thereafter reproduce new individuals and witness the decease of others as dictated by the age-specific birth and death rates. What path will total population take? Will it eventually grow or decline, or settle down to a stationary level? What will happen to its age-structure? Part of the answer to these questions is given by the propositions usually associated with the work of Lotka:

The proportional rate of change of the population will eventually become virtually constant. The rate of change may be positive, in which case population grows, negative, in the case of population decline, or zero. For any given set of age-specific birth and death rates this eventual rate of change (called the intrinsic growth rate) will be the same irrespective of the initial population and its age-structure. Moreover, the eventual age-structure will approach a particular pattern determined solely by the intrinsic growth rate and the age-specific death rates.

These are by no means trivial results and I shall not attempt to derive them here. ${ }^{1}$ They imply that a population 'forgets' its initial age-structure and that its eventual growth and age-structure depend only upon its mortality and fertility rates at different ages. Further insight can be gained by asking what determines whether the population eventually grows, declines, or stays zero? To answer this it is necessary to define the net reproduction rate. Consider 1000 female children just born. Some proportion of them will survive to the reproductive age-groups, and will have children of their own as

${ }^{1}$ They are derived in Pitchford (1974), Chapter 2. 
determined by age-specific fertility rates. The number of their children divided by 1000 is the net reproduction rate. If the number of children is, say, 1100 , the net reproduction rate is $1 \cdot 1$. Thus this rate is a measure of the capacity of women to replace themselves. If they are exactly replacing themselves it will be unity, and if they cannot replace themselves it is less than unity. The intrinsic growth rate of the population will be positive, zero or negative, as the net reproduction rate is greater than, less than or equal to one.

The case in which the net reproduction rate is unity is of interest because it seems to be the one implicit in some statements by the proponents of zero population growth. With this unit value it is, of course, still possible for population to grow. Suppose initially the population was weighted heavily towards the reproductive age-groups, then there will be a tendency to produce more children than is compatible with a stationary population. Hence it can be seen that if in a growing population the net reproduction rate is reduced to unity, the process of growth may continue for some time, because a growing population is almost certainly weighted towards the lower (and hence more fertile) age-groups. The order of magnitude of this phenomenon is illustrated by recent population projections made by the United States Bureau of the Census (1971). They suppose that fertility declines from 1970 to produce a net reproduction rate of unity by the period $1980-5$. For India the initial population is 576.0 million rising to 751.8 million in 1985 . It would take until the year 2040 for population virtually to stabilise, and by then its level would be 1206.8 million, or more than twice the 1970 figure. The same fertility experience for Australia, they estimate, would involve a rise in population from 12.4 million in 1970 to a virtually stationary figure of $16 \cdot 5$ million by 2020 . Population rises by almost a third and takes fifty years to stabilise. It is clear that policies to produce a stable population must look well into the future.

It has been emphasised that the assumption of the standard population model that age-specific fertility and mortality rates are constant, is not made because it is thought that this will be true. Indeed these rates are found to vary considerably over time. It is now appropriate to examine theories of population change which implicitly or explicitly attempt to explain such variations. 


\section{ARITHMETICAL THEORIES}

The simplest, most naive, but not uncommon approach is to assume that population grows at a constant positive exponential rate. Malthus talked of population tending to increase geometrically, whilst modern economic growth theorists frequently include such an assumption in their models. To be fair Malthus pointed to the possibility of various checks and restraints to net fertility, whilst growth theorists may defend their assumption by claiming a relevance for their models which encompasses a restricted time span. Nevertheless, it is often the practice to engage in elaborate investigations of the equilibrium properties of such growth models, so that unless it could be shown that movement to the equilibrium was rapid it would be hard to defend the assumption. Casual observation suggests that world population must be bounded above so that any theory in which the growth rate of population does not tend to zero cannot apply indefinitely.

Arguing partly on the basis of such an upper limit to population, Pearl and Reed (1920) suggested that populations would through time follow a path of the type given by the Logistic Curve, ${ }^{2}$ which has the property (among others) that population approaches an upper bound. The proportional rate of growth of population, they claimed, will adjust to the difference between the upper bound to population and its current level. Further, this growth rate becomes smaller the nearer the actual level to the upper bound. In effect they argued that human populations would behave in very much the same way as animal populations in a finite environment. At first they would increase rapidly when per capita resources were large, but later population growth would fall off, and tend to zero as the number the environment could 'sustain' was approached. Those who wish to pursue this approach further should consult the book by Orcutt et al. (1961: 50, 51) which describes the successes and failures of the approach, concluding as others have done that despite its limited success in population projections it has too inadequate an analytical basis to serve as a theory of human population growth.

2 This curve has the formula

$$
N(t)=\frac{a}{1+b e^{-c t}}
$$

where $a, b$, and $c$ are positive constants, $e$ is the exponential constant $(2 \cdot 71828$. ) and $N(t)$ is the population level at time $t$. 
The dangers implicit in any simple arithmetical projection of population are often overlooked by those who should know better. An extreme illustration of this fact is given by the fitting of a hyperbolic curve ${ }^{3}$ to United Staies population figures by Keyfitz; and its comparison with a logistic curve fitted to the data for 1800-1910. 'The least squares logistic moves toward an asymptote of 197 millions, while the hyperbola through 1850 and 1900 goes to infinity in 1923.' (Keyfitz 1968: ch. 9, p. 220).

\section{DEMOGRAPHIC TRANSITION}

This concept may be proposed either as a theory of net fertility change or as a summary of a process which seems to have taken place in many European and some other countries in recent times. However, in the latter form it has no predictive value, and would not warrant mention in a chapter devoted to theories of population growth. It would be interpreted here as suggesting an hypothesis about developments in countries which have not completed such a transition.

The mortality patterns which characterise many European and Western type economies are of comparatively recent origin. To quote Borrie (1970: 12-13):

By efficient death control is here meant levels of death rates which prevailed around 1960 throughout virtually all European countries (including European U.S.S.R.) and many countries peopled by Europeans, that is with infant death rates per 1,000 live births between about 20 and 50, with some 90 per cent of females born living to the end of the child-bearing period, and with expectations of life at birth between about 65 and 70 years. Such conditions were unknown to mankind until the twentieth century. . .

The high death rates which previously prevailed in these countries were usually also associated with high birth rates. An examination of nineteenth and twentieth century history of the area shows, with some exceptions, that falling death rates occurred at somewhat the same time as increasing industrialisation and urbanisation, and rises in literacy and living standards. Further, following the fall in death rates with some time lag, considerable and sustained declines

${ }^{3}$ The curve has the form

$$
N(t)=\frac{a}{t_{e}-t}, a, t_{e} \text { conștạnts, } t<t_{e}
$$


in fertility rates were experienced. Hence the tendency towards rapid growth implicit in the application of the new methods of medicine and hygiene, and in new ways of living, was eventually offset by reduced fertility.

This suggests that a pre-industrial society which experiences a process of economic development and industrialisation can expect a fall in death rates and later in birth rates so completing a transition from a highly inefficient reproductive system to a situation of low fertility and mortality.

However, for underdeveloped countries the process has already been following a rather different pattern. A fall in death rates seems to be occurring independently of economic development, mainly owing to the application of modern medicine. For these areas a vital question then is whether economic development is a necessary condition for falls in the level of fertility to occur? If so, they are condemned to a period of rapidly rising population which may even prevent the desired development. The theory of demographic transition is neither formulated sufficiently closely nor verified sufficiently satisfactorily for it to suggest an answer to this question.

\section{RICARDIAN THEORY}

In many countries most of the population are wage earners, so that if economic conditions affect fertility and mortality it will be partly through real wage levels. The real wage is a measure of the purchasing power of wage income, and is not to be confused with the money wage whose purchasing power will depend on the level of prices. Ricardo used the term 'wages' to refer to real wages. Suppose a subsistence wage is defined in such a way that if the actual wage received falls below the subsistence wage the women in the families concerned will have a net reproduction rate less than unity. From the analysis of the previous section the population must eventually decline (although if the initial age-structure involves a relatively large proportion in the lower age-groups there may be some lag before the decline sets in). Above the subsistence wage the better health, greater life expectancy and improved economic conditions of the family would lead to a net reproduction rate above unity. Ignoring the possible lags, the Ricardian theory could be summarised by saying that the rate of population growth would be greater the higher the actual wage compared with the subsistence 
wage, and would be negative if the actual wage fell below the subsistence wage. Assuming such a subsistence wage may be defined, the theory has considerable appeal as an explanation of population movements when the actual wage is below the subsistence level. When the wage is only a little above this level some decline in infant mortality and fall in the age of marriage, combined with a rise in family size could occur, so causing the predicted growth in population. For wage levels well above subsistence there does not seem necessarily to be a clear cut case that these determinants of net fertility will continue to raise the net reproduction rate. Certainly families are free to support larger numbers of offspring, and perhaps they may be willing to do this or ignorant of ways of avoiding it. Closer analysis of motives is required in these circumstances, and this point will be returned to shortly when Becker's work on fertility is examined.

Another difficulty about Ricardo's hypothesis is the definition of the subsistence wage. The theory loses a good deal of its content if this cannot be defined objectively, and many considerations would suggest that it would vary from one cultural group to another, and from one era to the next. The wage which would keep one group alive may be very different from that which would sustain another. There would seem to be a need for a theory of the determination of the subsistence wage in order to complete the analysis.

Becker (1960) has suggested an analysis of fertility which goes some way towards putting the subject in an economic context. Essentially, he proposes a treatment of children as consumer (and in some cases producer) durables. Assuming families have effective birth control techniques available to them, children may provide satisfaction to the family or may be regarded as an investment in a future income earning asset. Regarded as consumer durables, a family may spend more or less on a given number of children so resulting in higher or lower 'quality' children. Becker adds that this gives the children quality in the parents' eyes, but does not necessarily make them better from other points of view.

Becker goes on to develop these theories and comes to the conclusion that for Western-type economies an increase in income should have the effect of increasing both the quantity and quality of children. However, he felt that quantity would respond less sensitively to income than quality. 
Clearly empirical evidence is needed to sort out both the sign and size of these effects, and this will be examined later.

\section{FECUNDITY AND FERTILITY}

A possible approach to fertility is to consider its maximum value.

Assuming that a woman's fertile years lie between ages 15 and 49, that is a period of thirty-five years, and that she was married throughout the whole of this period, it might be quite possible for her to have up to twenty conceptions; but this is much above the average figure known to have existed in any community. In no society do all women marry at the onset of puberty, or stay married until menopause. Some do not marry at all; some marry and are widowed or die during their childbearing years; some marry but are infertile because of their own or their husband's sterility. Moreover, not all conceptions result in live births. Many societies also have customs which forbid or restrict intercourse for long periods after the birth of a child. Thus there are many biological, social and environmental factors which reduce average fertility well below the theoretical maximum, and the highest known average number of births to women by the end of their child-bearing years is about ten. This seems to have been the level attained by the early settlers in French Canada in the seventeenth century. The nearest modern approach to this is found in the Cocos Islands with a total of about $8 \cdot 8$ children, or the anabaptist Hutterites of North America whose fertility in 1946-50 also implied an average of about eight children by the end of the child-bearing period. (Borrie 1970: 29)

By comparison with these apparently maximal rates, India in 1961 had a total fertility rate of $6 \cdot 3$, whilst the Australian figure for 1961 was $3 \cdot 5$. At first sight it might appear that a useful approach to studying Indian fertility might be through an examination of factors which prevent attainment of maximal fertility, although this would not be fruitful for Australia. Such an approach, however, would need to be handled with considerable care. Thus, for instance, a comparison of total Indian and Hutterite fertility conceals the fact, common to many developing countries, that Indians marry much younger. A 'European marriage pattern' which would seem to have had a considerable impact on fertility in some parts of that area before and during the nineteenth century, involved late marriage and low marriage rates. ${ }^{4}$ Although this marriage pattern has not generally lasted into the twentieth century it is still a factor differentiating developed from underdeveloped countries.

4 See Hajnal (1965). 
At this stage a list of some of the more important factors which differentiate actual from maximal fertility may be useful. Age at marriage and proportions marrying have already been mentioned. If total fertility is compared for different countries, age-distribution is also important. A relatively high proportion of females in the more fertile age-groups makes for a higher total fertility, other things being given, and the fact that a rapidly growing population will probably have a large proportion of younger females can account for its high fertility. Such problems of comparison can be removed by examining age-specific fertility or by computing some standardised measure such as the net reproduction rate, or the intrinsic growth rate.

These measures, of course, conceal the sources of differing fertility. To continue the list, the survival of marriage is influenced both by divorce rates and by mortality rates, and the effect this has on fertility will depend on the incidence of remarriage. Fertility will also depend on the extent of illegitimate births as well as on the ratio of births to marriages. Multiple births seem to be genetically determined (and recently to be influenced by fertility drugs). It is unlikely that they would explain significant differences in fertility.

No simple, readily acceptable, theory of fertility would seem to have been formulated. Empirical testing of various hypotheses is needed, and the results of some of this work will now be surveyed.

\section{EMPIRICAL TESTING OF NET FERTILITY THEORIES}

Empirical investigation of the causes of fertility forms a considerable part of the study of demography. The resultant large and seemingly unsettled body of literature ranges, for instance, from examinations of the effect of income per capita to investigations of the influence of altitude on fertility. I have confined this section to a discussion of two recent general studies of fertility determinants (one of which is also concerned with mortality), and to some comments on the relationship between income and fertility. ${ }^{5}$

Crude birth rates are a resultant both of the age-structure of a population and of age-specific fertility rates. In studies of fertility it is essential therefore to separate out the influence of age-structure,

5 One possible determinant of fertility, the birth control programs of developing countries, is not dealt with here. A survey of these plans is given by Berelson (1969). 
working, if possible, with age-specific fertility. This consideration would appear to rule out for many countries the possibility of studying fertility from time series, for such fertility data are not available for long time spans. Hence, one of the characteristics of such investigations is that they have usually been carried out on the basis of cross-country or cross-regional studies at a given recent date. Exceptions to this approach are the short-run studies of fertility which aim, for instance, to study its behaviour over the trade cycle.

Using data from thirty-seven countries drawn from the period 1947-57, with a wide geographic distribution and a considerable range of income per capita, Adelman (1963) examined fertility of five-year age-groups from 15 to 50 in relation to a number of socioeconomic variables. These determinants were income per capita (Y), urbanisation (represented by non-agricultural employment (I)), the mother's level of education (represented by an average of the literacy index and an index of newspaper circulation per capita (E)), population density (P), and infant mortality. This latter variable was found to be highly correlated with income per capita so that its separate contribution would be difficult to assess. It was dropped from the model because preliminary tests showed it not to be statistically significant. ${ }^{6}$

Very briefly, it was found that income per head for some agegroups appeared to be a significant determinant of fertility, but that in general its effect was likely to be small, so that even if income rose by a large percentage its impact on fertility would be slight. Of all the possible explanators of fertility, the education index and population density were the most significant, and it also appeared that variations in these entities would account for considerable differences in fertility.

It cannot be said that the results are particularly decisive, especially as the applicability of the cross-country approach to any individual country must be open to some doubt. However, the positive association of fertility with income per capita lends some support to Becker's views, though the fact that it is small and in most cases insignificant

- The equation tested was

$\log _{e} b_{i}=a_{0 i}+a_{1 i} \log _{e} Y+a_{2 i} \log _{e} I+a_{3 i} \log _{e} E+a_{4 i} \log _{e} P$ where $b_{i}$ is the number of live births per thousand to females in the ith agegroup. The logarithmic form implies that the $a_{j i}$ coefficients may be interpreted as elasticities. 
makes the support weak. On the other hand education and population density may have an appreciable effect on fertility.

Age-specific mortality was also investigated, the age-groups chosen being $0-1,1-4$, and thereafter at five-year intervals. ${ }^{7} \mathrm{Up}$ to the age of 50 it is found that there is a significant negative relationship between death rates and income per head. The rate of growth of income is also negatively associated with death rates in the same age-groups. Further, up to age 50 lower death rates would appear to be associated with industrialisation. Mortality is negatively correlated with medical care, particularly from age 50 onwards. Indeed it is the only statistically significant variable for the age-groups $50+$.

Collver et al. (1967) have investigated variations in fertility in Taiwan for 1961 among 292 local administrative units. Taiwan's population in the 1951-6 period had reached a rate of natural increase of 36.7 per thousand, but in the next year the crude birth rate dropped from $44 \cdot 5$ to $40 \cdot 2$ per thousand and this was followed by a steady decline so that "by 1962 the rate of natural increase was below 30 per thousand and falling rapidly'. These facts and the ready availability of a large amount of geographically distributed data make this experience an extremely interesting field of study. Their first step was to correlate birth rates per thousand married women in total and for the age-groups 20-24 and 35-39 with each one of the following variables taken by itself:

1. logarithm of population per square mile,

2. percentage of male labour force in agriculture and fishing,

3. distance to nearest urban centre,

4. percentage of females aged 12 and over who completed primary school,

5. annual net migration rate,

6. crude death rate,

7. death rate of children $0-4$,

8. sex ratio.

7 Adelman fits the equation

$$
\log \mathrm{m}_{1}=\mathrm{c}_{0_{1}}+\mathrm{c}_{1_{1}} \log \mathrm{Y}+\mathrm{c}_{21} \frac{\Delta \mathrm{Y}}{\mathrm{Y}}+\mathrm{c}_{3_{1}} \log \mathrm{I}+\mathrm{c}_{4^{\mathrm{i}}} \log \mathrm{H}
$$

where $m_{i}$ is the number of deaths per thousand in the ith age-group; $Y$ and $I$ are, as before, per capita income and the non-agricultural employment index; $\frac{\triangle Y}{Y}$ is the rate of change of per capita real income; whilst $H$ is a health index (measured by the number of physicians per capita). 
It seems likely that several of these explanatory variables would be highly correlated so that a shorter list would be necessary for a multiple regression exercise. Even in this reduced list variables 2 and 3 are highly correlated with density and the result of the multiple regression study was that only density and education appear to produce significant and large effects on fertility. A further finding was that 'the big reductions in fertility have been made by married women over the age of 30 , indicating that family limitation rather than postponement or spacing of children was the predominant motive in the adoption of fertility controls by married women in Taiwan'. Income per capita was not included in the analysis, but it is interesting that education and density were also the significant explanators of fertility in Adelman's study.

Various economic theories have stressed income as important in choices about family size. Yet it is fair to say that the evidence for such a relationship is far from convincing. Assuming that Adelman's results could be regarded as supplying evidence on possible long-run effects they suggest a small and not very significant positive relationship of fertility to income. A positive relationship has also been observed over the trade cycle (see Galbraith and Thomas 1941). Yet both fertility and desired family size show a negative relationship to income when a cross-section through the various income earning brackets of a society at a given point of time is taken (see, for example, Simon 1969). The justification for a theory of fertility based on income would seem to be very slight.

Adelman's study of mortality does, however, lend support to the approach which stresses a positive relationship between per capita income and the population growth rate. Whilst there is little evidence to suggest that birth rates respond to per capita income, the behaviour of death rates does seem to be so related.

\section{POPULATION GROWTH IN AN ECONOMYC CONTEXT}

Suppose the productive environment is such that land must be regarded as a fixed factor. Here all resources will be treated as renewable. Exhaustible resources require a different type of analysis and this is left to Chapter 5. A sensible representation of such environmental limitations will imply that as more labour and capital are employed output per head will fall. If population continues to grow in this situation, output per head must eventually fall below a 
subsistence level. Clearly, any theory in which population growth is regarded as independent of economic conditions is inapplicable in this context.

Population growth must then be related to economic conditions, and there are broadly two ways in which this may happen. The first is through some rational planning of fertility and migration taking account of community preferences so as to achieve desired population and output movements. This approach is of very recent origin, and is the aim of some of the birth control programs of underdeveloped economies. Aspects of this matter will be dealt with in Chapter 5. Here we shall explore the implications of the second approach, which is based on the link between mortality and output per head and which, from the discussion in previous sections, seems to be plausible. Many economists have written on this theme, the earliest and most notable contributions being those of Malthus and Ricardo. ${ }^{8}$ We have seen earlier in the chapter how complicated the process of population growth can be when its age-structure is taken into account. However, it is broadly true that a fall (rise) in mortality rates will produce a rise (fall) in the rate of population growth, and it is this association which economists have assumed in their theories.

Although Ricardo's analysis of this problem appeared in 1817 it remains one of the most fundamental treatments of the subject. Ricardo not only supplied a description of the movements of population and economic variables through time, but he also incorporated a theory of income distribution amongst various economic classes in his analysis. Indeed his system required such a theory for he assumed, as was noted above, that the population growth rate would be associated with the real wage level. This will give much the same results as would the assumption of an association with output per head, for wages and per capita output move more or less together in his model. The bulk of the population were wage earners, and as well there were capitalists who owned and organised business enterprises, and landlords who owned resources, which earned them rent. Now land was not regarded as homogeneous, indeed there was supposed to be a large number of grades of land, the supply of each being fixed. The profit motive would ensure that

${ }^{8}$ See Blaug (1958), Bowley (1937), and Tucker (1960) for discussions of Ricardo's theory. A recent analysis of growth with a fixed factor is given by Niehans (1963). 
the best land was used first and that as output expanded land would be brought into productive use in order of decreasing efficiency. Rent was the amount left to land holders from sale proceeds after wages and capital costs had been paid. Obviously it would pay landlords to leave a piece of land idle until rent for that quality land was either positive or zero. (If it were zero he would be indifferent whether he left it idle or used it in production.) In given circumstances how much land would be used? Consider bringing one more unit of land into production. It will certainly pay the landlord to do this if its rent is positive, so that provided additional land is availables it will be used for production up to the point at which the rent on the last piece to be used is zero. This unit of land could be called the marginal unit. Assuming full employment of labour and capital, these factors will be used in co-operation with land up to the point at which rent is zero on the marginal unit.

Now suppose a situation in which population is growing because wages are above the subsistence level. With high wages and a growing population more land will be brought into use to satisfy the consequent growth in demand for goods. However, this land will be inferior to that already in use with the result that labour and capital employed on it will be less productive than that employed elsewhere. Now it has been shown that there will be no rent on marginal land so that all the earnings from such land go to labour and capital. However, inferior units of land yield smaller returns per unit of capital and of labour than superior land, so that there will be pressure for the return to capital, and the wage to fall. Competition for jobs will mean that wages will fall to workers not only on the marginal unit but throughout all employment. The fall in wages means a reduction in the rate of population growth.

While population grows there will continue to be a downward pressure on wages, and this will go on until wages reach the subsistence level. At this point population growth will cease and the system will have reached a stationary state with subsistence wages. Profits will be at minimal levels, for if they were not, extra saving would be generated and new capital produced to generate further

- Additional land is always available if one assumes that productive efficiency of some land is very low indeed, so that production from that land involves astronomic costs. While Antarctica remains unexploited we cannot say that all available supplies have been used. 
growth. Resource holders (other than the owners of marginal land) would be well off, being the owners of the only really scarce factor in the system. And so the economy would continue in its dismal state with high death rates to offset high birth rates and poverty amongst the working classes, unless new discoveries, or technical change operated to start a further growth process.

Ricardo was writing about a situation in which agriculture was an important sector of the economy. The story would be little different for any other renewable resource than land. It could be considerably altered, however, if high quality resources (either renewable or exhaustible) were relatively plentiful, and if manufacturing industries, in which increasing returns to scale were possible, existed. Population growth then brings economies of scale in manufactured goods production which can cheapen such goods even if resource prices are rising. Technical progress could then also be important as the high level and large scale of productive activity generated new skills and promoted research. Wages and profits could well rise in such a context, and population could grow rapidly. Wrigley (1967) has given an interesting interpretation of the Industrial Revolution as a change from a system based upon vegetable and animal raw materials to one which relied largely on inorganic raw materials, particularly coal. The former system was limited by the supply of available land, whereas in the latter the limits to growth were greatly expanded. Exhaustion of scale economies, slowing down of technical change and decreasing efficiency and exhaustion of resources are the influences which would eventually bring the system back to a Ricardian world and the stationary state.

Although the above analysis has been argued in the framework of a free enterprise system it should be noted that the results would be much the same whatever the political organisation. As long as resources are limited, and the population grows if rewards to workers exceed the subsistence level, the same basic processes must take place, and the stationary state is the inevitable outcome.

The stationary state in this analysis seems a most undesirable situation, and for this reason has a bad name in economics. It is interesting that this attitude has persisted even amongst modern writers. Thus Niehans (1963), writing about his Ricardian-type model, refers to its 'destiny of stagnation' (p. 355) and elsewhere he remarks that 'the most desirable pattern, i.e., eternal growth com- 
bined with continuous improvement of living standards seems to be unattainable under diminishing returns' (p. 365). Although the Ricardian stationary state involved a meagre subsistence wage rate and high death rates in lower age-groups, it is not reasonable therefore to condemn all stationary states. They imply a situation in which net reproduction rates are zero, and with rational planning or persuasion this may be associated with low fertility and hence low death rates and a high standard of living. Indeed, the attitude of many observers today is that a stationary state is not only inevitable but is also desirable. The concept of a balance between human activities and the natural environment is very much in vogue at present and would seem to have much to commend it. In Chapter 2 it was seen that it is at least conceptually possible to seek amongst stationary states that which is the most desirable, and hence to calculate optimum population.

Finally, it should be noted that some authors have pointed out that a stationary state with zero population is possible. Niehans has suggested that if output per head is initially low population and capital may both fall and eventually become zero. Population falls because of the higher death rates whilst capital falls because a high proportion of income goes to consumer goods, so that not enough is left over to make good the depreciation of capital. The same type of result has been envisaged by some writers on the subject of pollution. Pollution is added to by productive activity, but decays away naturally at a certain rate. If the stock of pollution is large and its decay rate relatively small, it has been pointed out by Forster (1972) that there could develop an unstable situation with pollution adversely affecting output, and hence output declining perhaps to a zero level. Population, of course, must also decline and eventually become zero. It should be noted that for both these authors the zero-production stationary state occurs because the initial situation of the economy was unfavourable, either with a low per capita output or a high pollution stock. From other starting points stationary states with positive population levels would be approached.

\section{REFERENCES}

Adelman, I. 1963. 'An Econometric Analysis of Population Growth', American Economic Review. 
Becker, G. 1960. 'An Economic Analysis of Fertility', in National Bureau of Economic Research, Demographic and Economic Change in Developed Countries, Princeton.

Berelson, B. (ed.), 1969. Family-Planning Programmes, An International Survey, Basic Books, New York.

Blaug, M. 1958. Ricardian Economics. A Historical Study, Yale University Press, New Haven.

Borrie, W. D. 1970. The Growth and Control of World Population, Weidenfeld and Nicolson, London.

Bowley, M. 1937. Nassau Senior and Classical Economics, Allen and Unwin, London.

Collver, A., Speare, A. and Liu, P. 1967. 'Local Variations in Fertility in Taiwan', Population Studies.

Forster, B. A. 1972. 'A Note on Economic Growth and Environmental Quality', Swedish Journal of Economics.

Galbraith, V., and Thomas, D. 1941. 'Birth Rates and the Interwar Business Cycle', Journal of the American Statistical Association.

Hajnal, J. 1965. 'European Marriage Patterns in Perspective', in Glass, D. V. (ed.), Population in History, Edward Arnold, London.

Keyfitz, N. 1968. Introduction to the Mathematics of Population, AddisonWesley, Reading, Massachusetts.

Niehans, J. 1963. 'Economic Growth with Two Endogenous Factors', Quarterly Journal of Economics.

Orcutt, G. H., Greenberger, M., Korbel J., Rivlin, A. M. 1961. Microanalysis of Social Econonic Systems: A Simulation Study, Harper \& Brothers, New York.

Pearl, R., and Reed, L. J .1920. 'On the Rate of Growth of the Population of the United States since 1790 and its Mathematical Representation', Proceedings of the National Academy of Sciences, VI.

Pitchford, J. D. 1974. Population in Economic Growth, North-Holland, Amsterdam.

Simon, J. 1969. 'The Effect of Income on Fertility', Population Studies.

Swan, T. W. 1956. 'Economic Growth and Capital Accumulation', Economic Record.

Tucker, G. S. L. 1960. Progress and Profits in British Economic Thought 1650-1850, Cambridge University Press, Cambridge.

United States Bureau of the Census 1971. The Two-Child Family and Population Growth: An International View, U.S. Government Printing Office, Washington, D.C.

Wrigley, F. A. 1967. 'The Supply of Raw Materials in the Industrial Revolution', in Hartwell, R. M. (ed.), The Causes of the Industrial Revolution in England, Methuen, London. 


\section{Optimum Population}

THE preceding chapter explored some consequences of population growth being responsive to economic forces. For a country well endowed with resources population growth at a constant or even increasing rate for a long time was seen to be quite compatible with constant or rising living standards. Eventually, however, such a situation must come to an end (unless the science fiction hypothesis of never-ending technical progress is found to hold), and a stationary state at subsistence consumption levels will rule. Stationary states need not involve subsistence consumption, so that it would seem preferable to find some way of controlling population growth and choosing an eventual level which was more desirable than this. Controlling growth does not, of course, imply compulsion on individuals to conform to dictated standards. There are possibilities (as will be seen in Chapter 5) of working by persuasion and incentives through individuals' preferences to achieve socially desirable rates. Indeed it will be later argued that some form of collective action may bring people closer to their true preferences than will a complete absence of population policy.

The process of controlling economic growth may be conceptually broken into two parts. The first is the endpoint towards which the system is to be guided whilst the second is the process of deciding how and to what extent to influence its behaviour at any point of time. Putting the two parts together the desired path of the system will be discovered. This division is the basis of the difference between this chapter and the following one. Here we shall look at the notion of optimum population, regarding it as the endpoint towards which an economy may choose to move, whilst Chapter 5 deals with ways of getting there. To a purist this distinction is artificial. It would be 
preferable, he would claim, to calculate both the path and the endpoint as the solution to the single problem of what is the desirable development for an economy. However, it is certainly easier to understand the choices to be made if the proposed partition is undertaken. Moreover, it accords with the commonsense of the problem to ask first where are we going, and secondly how do we get there?

We have already defined optimum population in Chapter 2 to be that stationary population level which when appropriately supplied with capital equipment (such as factories, roads, bridges, etc.) results in the maximum consumption per head of population, whilst maintaining a constant quality and supply of renewable resources (and exploiting exhaustible resources at an appropriate rate). Here we shall adapt the definition slightly so that it refers to maximum welfare per head of population, and shall later make clear what that means.

It is not only in the economic literature that the idea of an optimum is implicitly or explicitly advanced. Statements about overpopulation are common not only for less developed areas, but lately for the United States and other advanced countries. It used to be commonly said (but is not now such a popular view) that Australia was underpopulated. Such ideas imply an optimum level or range for population, but do not usually make clear how the optimum is formulated. Indeed any statement about desired current and future population growth rates requires only a few logical steps before some desirable endpoint population is implied. If importance is to be judged by public concern, and if public concern is to be judged from the media, there are very few more important issues today than those which suggest a concept of optimal population. Of course, getting to an optimum from some initial point involves the really difficult policy considerations, and these may be of such a magnitude that they overshadow the optimum issue. If, for instance, a country was regarded as having double its optimum population and was still growing at 2 per cent per annum the immediate difficulty of preventing yet a further doubling would eclipse the issue of reaching optimum population. Yet it is nevertheless true that some idea of an optimum motivates the current policy in that country, although reaching the optimum may be far off in the future.

The optimum population concept employed by some earlier 
writers differs in some fundamental respects from that used here. Their concept was directed at a more immediate question than that of the endpoint of a growth process. At a given time a country has particular resources, capital and technology. They asked what population should be at that time to achieve some social objective such as maximum output per head. Thus they were concerned with an aspect of the growth process, and as circumstances changed so the optimum in this sense would change. Unfortunately it would seem that their notion is probably not very relevant even for the growth process. To see this suppose actual population was higher than their optimum. There would be no acceptable policy which would quickly bring the actual population to the desired level, and by the time one could be implemented the optimum would probably have changed because of capital accumulation. An operational approach to controlled growth should take account of the way populations move.

Not all writers have taken the view examined above. Thus CarrSaunders (1931: 26) states:

there is for any piece of land, when a certain amount of skill is available, a point where, by the application of a definite amount of capital and labour, the maximum return per head is reached. (My emphasis.)

Benham (1928: 249) in an article on Australia's future population says:

The quantity of population alone will be supposed to vary, all other factors whatsoever remaining the same, except two: capital and, in a restricted sense, organisation. It will be supposed that a population of any given size is somehow supplied with capital adequate to its size.

These authors in allowing capital to vary in the calculation are coming close to the concept of optimum population to be studied in succeeding sections.

\section{ALTERNATIVE CRITERIA FOR OPTIMUM POPULATION}

It was seen in Chapter 2 that if society wishes to maximise output per head it should choose a population and capital stock so that it is at the point at which returns to scale are just exhausted, and the net marginal product of capital is zero. The marginal product of labour would be equal to its average product. Let us continue with 
the framework of the discussion in Chapter 2 (where, it will be recalled, technological knowledge is taken to be unchanging and goods are produced in fixed proportions), and ask what alternative criteria may be relevant to the problem, and how their use would affect the optimum population level.

Maximum output per head is an appealing criterion because it suggests that on average individuals are in the best possible position. Some other criteria that have been proposed would seem to reflect judgments about society as an entity distinct from the individuals who live in it. This seems true of the total output criterion. Figure $4 \cdot 1$ (which reproduces the constructions of Chapter 2, especially Figure $2 \cdot 3$ ) shows total output maximised at $\mathrm{N}^{\prime}$ which is certainly greater than $\hat{\mathrm{N}}$ (the per capita optimum). To get maximum output all factors are employed to the point at which they can contribute

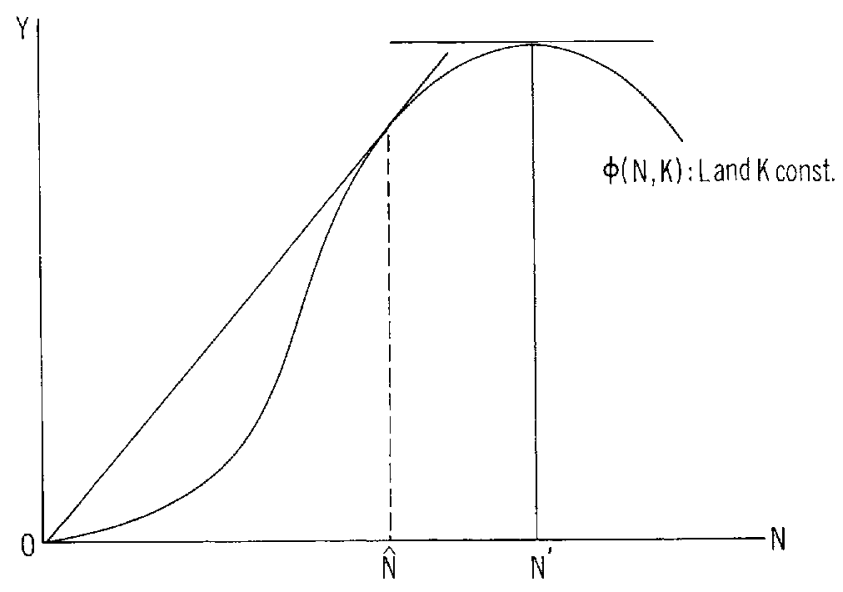

Figure $4 \cdot 1$

no further to output, hence their marginal products are zero. At $\mathrm{N}^{\prime}$ the marginal product of labour is zero, as is indicated by the tangent to the output curve becoming horizontal. When comparing $\hat{\mathrm{N}}$ and $\mathrm{N}^{\prime}$ in Figure $4 \cdot 1$ it must be remembered that capital is held constant so that the marginal product of capital is not necessarily zero for each point. Nevertheless, reasonable assumptions about production may be made which preserve the result that with both capital and 
labour variable, the total output criterion implies a higher optimum population. ${ }^{1}$

One could imagine the total output criterion being pursued by a society particularly interested in military power. With a large output the possibility exists of supporting large defence expenditures, and with a high population the armed forces could be large. ${ }^{2}$ Perhaps there are other justifications for it, but it does not seem to be a commonly accepted notion.

Returning to approaches which concentrate on the average individual it should be noticed that the average product criterion does not distinguish in some respects between very poor and very rich countries. Certainly output per head in a rich country will be higher than in a poor country, but it is implied that giving the average inhabitant of a rich country $x$ more units (of our composite good) improves his wellbeing by as much as the same gift would raise the

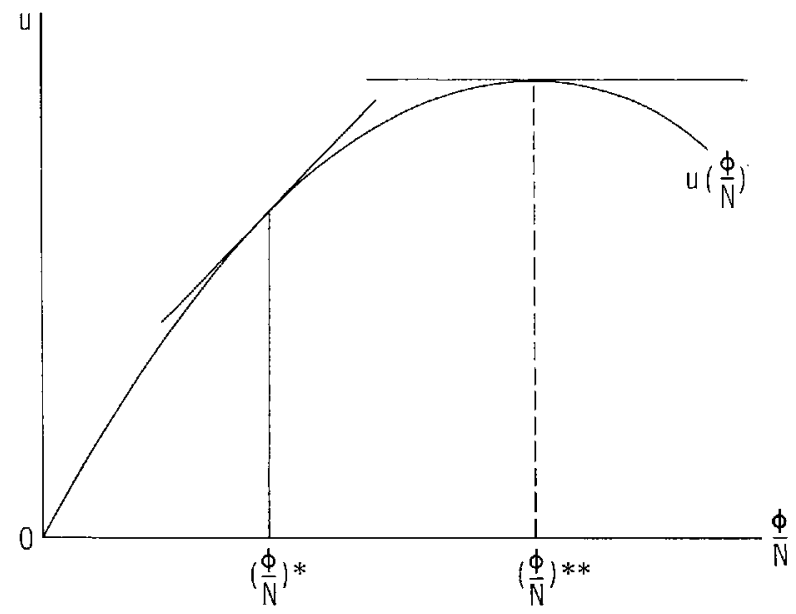

Figure $4 \cdot 2$

wellbeing of a poor country's resident. Subjective comparisons such as this are difficult to test, but, nevertheless, there would be considerable support for the view that a given increment would be valued more highly by an individual when poor than when rich. To elucidate this proposition further we need a welfare or utility

1 See Pitchford (1974), Chapter 5.

- Although this may not always be a requirement for strong defence. 
function, and this is illustrated in Figure 4.2. Output per head is plotted on the horizontal axis whilst the vertical axis measures valuations to be associated with each level of per capita output. It is natural to call the slope of the utility curve marginal utility. To give effect to the valuation proposition posed above it can be seen that as output per head rises, the value of an increment (that is, marginal utility) falls. The utility function is said to exhibit the property of diminishing marginal utility. Figure 4.2 is drawn to illustrate a further possible property of the utility function. At $\left(\frac{\phi}{\mathrm{N}}\right)^{* *}$ it can be seen that utility has ceased to rise, and further increments in $\frac{\phi}{N}$ would cause it to fall. Thus marginal utility is zero or, putting it another way, the community is satiated with goods. Whether this is ever possible in the range of feasible outputs is a debatable question, but assuming it is possible, its implications for optimum population are as follows. Write the utility function

$$
\mathrm{u}=\mathrm{u}\left(\frac{\phi}{\mathrm{N}}\right)
$$

which may be read as stating that the community's welfare depends on its per capita output. Then if levels of output per head equal to or greater than $\left(\frac{\phi}{\mathrm{N}}\right)^{* *}$ are feasible the greatest utility is nevertheless reached at that level. What if this satiation point cannot be reached? In this case it is clear from Figure $4 \cdot 2$ that the highest value of utility is achieved when output per head is at its highest level, say $\left(\frac{\phi}{\mathrm{N}}\right) *$. But we have already established what determines maximum per capita output in Chapter 2. Thus we may conclude that unless satiation is possible the introduction of diminishing marginal utility makes no difference to the optimum population level or the criteria which distinguish it.

Of course it is an oversimplification to say that the welfare of a community depends solely on output per head. Numerous other things must also be considered, and we shall see what difference is made by some of the more important possibilities. First consider the absolute size of population in a given country. As this economy must have given geographical features and area, this amounts to saying that an individual will be concerned about the density of population 
in his country. To some extent it is possible for an individual to move his residence within a country to get closer to the desired density, but problems of crowding or sparse settlement may still concern a community even after such adjustments are made. Hence, for a representative individual, we may wish to write

$$
\mathrm{u}=\mathrm{u}\left(\frac{\phi}{\mathrm{N}}, \mathrm{N}\right)
$$

to express the fact that welfare depends on the level of population as

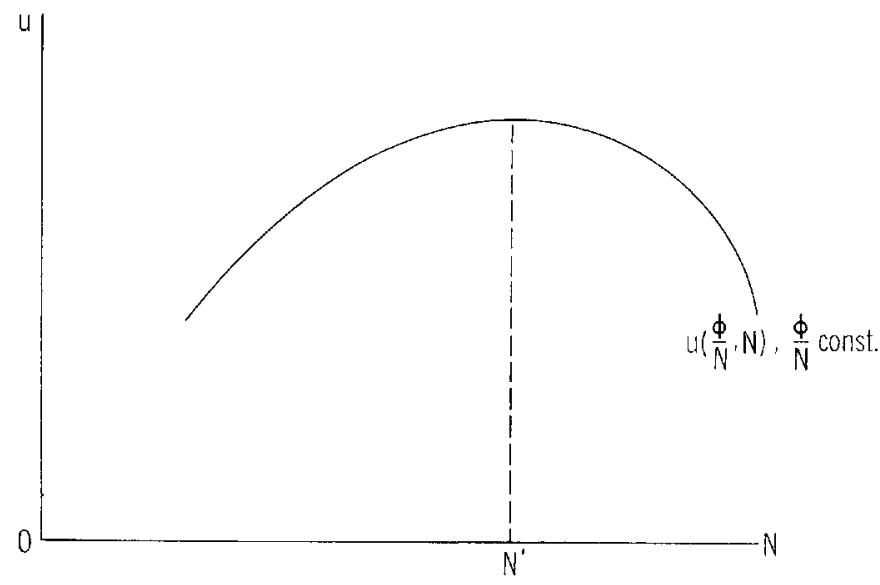

Figure $4 \cdot 3$

well as on output per capita. A plausible form for this additional aspect of welfare is shown in Figure $4 \cdot 3$. For a given $\frac{\phi}{\mathrm{N}}$, utility first increases then decreases, as crowding becomes greater. Will optimum population now be larger or smaller than under a solely output per head criterion? The answer may be found by examining the solution to the earlier problem, and asking whether at that population level a decrease or an increase in population is necessary to raise utility. Putting the question another way, we wish to know whether a typical individual would then be willing to give up some consumer goods so as to have more or less population? If he could be expected to feel overcrowded, then a smaller population would be optimal. However, there is nothing in the problem posed 
which suggests that the answer must be in one direction or the other. It all depends on the values attached to different densities.

One factor about which there will be no choice with a stationary population is average family size. Of course scope will exist for diversity in the number of children per family, but we have seen in Chapter 3 that with given age-specific mortality rates the average family size for an unchanging population level is fixed. If a stationary state is to be maintained with Western mortality patterns the average number of children per marriage would be about $2 \cdot 2$, irrespective of the absolute size of the population.

Another class of elements which could be added to the utility function is the enjoyment of so-called environmental factors. These include national parks, recreational facilities, clean air and water, and many other resource oriented entities which make for improved 'quality' of life. Such matters will be investigated when resources are explicitly introduced in later sections.

The way in which income and wealth are shared amongst classes in society is crucial to the assessment of the welfare aspects of any situation. This matter has been neglected so far by looking only at the average picture. It is not part of the economist's role to make judgments about the way income should be distributed, but he can contribute something to the understanding of the problem. In the first place if output per head is maximised there is a sense in which distributional problems are less than in any other situation. To see this compare the maximum value of output per head with some other value, and take the case where this other situation involves the same population level but less output than the optimum. (Other cases give the same conclusion.) Then it is clear that by choosing the optimum rather than the other value no one need be made worse off, and at least one person can be made better off.

Secondly, it is possible to deduce something about the earnings of wage earners and capitalists from the marginal products of labour and capital. Take labour, for example. The marginal product of labour is a physical magnitude measuring the extra output produced by an extra unit of labour. A competitive firm will value this extra output at the market price to get the value of the marginal product of labour. Now the cost of employing an extra person is his wage, so that if the firm is acting to maximise profits, it will offer a level of employment so that the value of the marginal product of labour is 
equated to the wage. If, for instance, the value of the marginal product of labour exceeds the wage it will pay to expand employment, for an increment in labour provides more in revenue than it costs. Competition for jobs will ensure that the wage is the same for all with the same skills. ${ }^{3}$ The reward to capital can likewise be related to its marginal product, ${ }^{4}$ and if land is introduced rents can be similarly treated. Now at the optimum the net marginal product of capital is zero so it would seem that labour and landholders would be sharing the whole of output between them, and capital would have a zero share. This is just a reflection of the fact that we are looking at the endpoint of a growth process where capital has essentially become a free good. The reward to capital need then only be sufficiently high to enable the replacement of depreciating items. We shall later introduce land explicitly and ask how this affects the above results.

The next aspect of utility to be examined also involves distributional considerations, but essentially of a different dimension. In any process of economic change over a reasonably long period of time, opportunities will exist for different patterns of treatment of different generations. If we invest heavily today, future generations will thereby be better off, whereas high consumption now would make present generations relatively better provided for. How should a society value a particular level of output per head now as compared with the same amount available, say, twenty years hence? Some would answer that they are equally valuable, for a society, being a continuing entity, should not discriminate amongst generations. Others would argue from what seems to be the attitude of individuals towards this matter. Consider a person evaluating his consumption of $x$ units of goods now as compared with the same number of units next year. It is often claimed that he would value those available now more highly than those available next year, because humans are basically impatient. If this is so he is said to discount future utilities at a positive rate. If society discounts in this way what will be the effects on optimum population? This question will be dealt with

With monopoly there are additional considerations which suggest that labour will be paid less than the value of its marginal product.

1 Strictly this is so provided some drastic assumptions are made about the nature of the capital used. Unfortunately, this area of economics is one of the most difficult and controversial of all. Nevertheless, the simple concept of the marginal product of capital often indicates the same sort of result as more complex notions. 
more fully in the following chapter, but something can be said here about the condition for an optimal stock of capital. The discount rate can be thought of as a concept analogous to an interest rate. If a community discount rate is decided on, the condition which will determine a stationary optimum situation is derived as follows.

Imagine a one unit reduction in this period's consumption which is invested in capital. The extra capital produces extra output next period as measured by the marginal product of capital. So next period the community will have the extra capital and an amount of extra output given by the marginal product of capital. ${ }^{5}$ Now with a given discount rate, say 5 per cent, the community would have made the investment only if for the sacrifice of one unit of consumption now it gets at least 1.05 units next period. Hence it can be seen that it will continue to invest in new capital until eventually the marginal product of capital is brought to equality with the discount rate. Thus with a positive discount rate the return to capital does not fall as low as when discounting is absent (that is, the discount rate is zero).

The above discussion would seem to have covered the main factors which could influence the utility function. It is now appropriate to allow in a more satisfactory way for a variety of goods. So far it has been assumed that goods are produced and consumed in fixed proportions. In the next section it will be shown how to relax this assumption and how the results differ when this is done.

\section{THE MANY GOODS CASE}

Suppose there is a finite number of goods, say $\mathbf{n}$. We could say that a reasonable description of society's welfare is that it depends on the supplies of each good per head of population, which may be written

$$
\mathrm{u}=\mathrm{u}\left(\frac{\phi_{1}}{\mathrm{~N}}, \frac{\phi_{2}}{\mathrm{~N}}, \ldots, \frac{\phi_{\mathrm{n}}}{\mathrm{N}}\right)
$$

where $\phi_{1}$ is the output of good 1 , and so on.

Now a utility function of this type enables comparison of the welfare gained or lost from exchanging a unit of good i for one of good $\mathrm{j}$. Thus, in effect if it is to be at all meaningful, a utility function

becall that it is the net marginal product of capital which is being discussed. Depreciation has already been allowed for. 
implies a set of prices which will be appropriate for any particular pattern of supplies. Rather than work with marginal utilities it is more constructive to use these prices in deriving results applicable to optimum population. If we multiply the output of each good by its price we can add the values of outputs of all goods to get a measure of national output. Utility will then be maximised when national output per head is maximised.

First look at capital in the industry producing good $i$. The result is completely analogous to the previous case, for the employment of capital will be increased to the point at which its net marginal product is zero. The condition for optimal employment of labour in each industry is also simple to derive. The labour force will be distributed optimally between industries when the value of the marginal product of labour from producing one good is the same as for producing any other good. If it were not we could shift labour from one industry to another so as to raise the value of national output per capita.

Lastly, imagine adding one more unit of population and hence labour to the economy. This will raise the value of per capita national income by an amount determined by the value of the marginal product of labour in the sector in which it is employed. (It does not matter which sector is employing it for, as was shown, the value of the marginal product has to be the same in each sector.) At the optimum the value of the marginal product of labour (in each sector) will be equal to the value of national output per head. This is just a slightly more complicated version of the 'batting average' rule discussed in Chapter 2.

What now can be said about returns to scale properties of the optimum population point? Two cases are possible. First each industry could, at the optimum, be operating at the point that just exhausted scale economies. This is completely analogous to the case discussed in Chapter 2. Secondly, at least one industry may operate so as to be subject to decreasing returns to scale. In this instance it can be shown that at least one other industry must be in the increasing returns range. ${ }^{8}$ The operating scale of each industry can be decided only when the problem is specified more fully than has been done here.

So we no longer have the rule that each industry has expanded so ${ }^{6}$ See Pitchford (1974), p. 132. 
as just to exhaust scale returns. The problem when a varying composition of output is allowed, has become considerably more complex.

It is, however, worthwhile to say something about the organisation of industry when increasing or decreasing returns to scale exist. When there are a large number of sellers each of which supplies a small proportion of the market it is unlikely that any single seller can exert a significant effect on the price of the product. This situation is one of competition, and is quite compatible with decreasing returns to scale. However, it is unlikely to be compatible with some forms of increasing returns to scale as will be shown. The factors which produce increasing returns to scale may be divided into two classes. First there are those matters internal to the firm (called internal economies) which make for greater efficiency at larger scales of operation. An example is provided by the contrast between handloom and factory methods of weaving. The other source is from so-called external economies where the benefits from larger size accrue from sources outside the control of the firm (and the rewards to be gained from expansion accrue outside the firm). If there are internal economies it pays competitive firms to amalgamate and so keep reducing their costs, so eventually the market is no longer competitive. With external economies competition could still exist, but subsidies would be required to get the industry to expand to an appropriate size. Monopolies pose problems of income distribution and of possible output restriction which may require some form of public control.

The neat solutions of the simplified problem no longer appears in the many commodity case.

\section{INTERNATIONAL TRADE}

A country which, relative to other countries, has a large population and/or large resources and capital stock may well be insulated from many of the effects of international trade. This is because it supplies such a considerable part of world markets (of its exported goods) and demands such a large share of world supplies of its imported goods, that its own domestic circumstances are the principal determinants of world prices of the goods it trades. For such an economy a calculation of optimum population would need only minor correction to take account of international trade. At the other extreme is the country which is small so that its consump- 
tion of imports is a small proportion of world trade in the goods concerned. Its domestic activities have little effect on world prices, and as world prices change so its optimum population will alter. The intermediate case requires that in assessing the effect of any domestic change the impact on foreign countries must be analysed, and then the effect of these foreign repercussions on the domestic economy must be reckoned with. Here we shall concentrate on the more straightforward case of the small country which exerts no significant impact on world prices.

Trade may be thought of as the process of exchanging exported for imported goods. If, say, world demand rises and hence export prices rise, the economy can exchange the same volume of exports for a greater volume of imports. Thus it is natural to define the terms of trade as the ratio of export prices to import prices, and to note that for our small country an improvement (rise) in the terms of trade will mean it is better off. One of the most difficult aspects of the determination of optimum population in this case arises because of uncertainty about future movements in the terms of trade. An informed calculation would require forecasts of future movements, coupled with estimates of the reliability of these forecasts. To illustrate the sorts of issue involved we shall consider the question of what happens to optimum population when a change in the terms of trade (known with certainty) takes place. This discussion will also be informative about another matter, namely the difference between a no-trade solution (as considered up till now) and one in which trade takes place. The reason for this is that the opening up of trade must mean a larger demand for exportable goods than when the country was not trading, and hence an improvement in the terms of trade. Thus, whenever an improvement in the terms of trade is discussed the accompanying analysis also covers the effects of the opening up of trade.

Suppose our small country experiences a rise in export prices and a fall in import prices. The most probable result would be that exportables industries would expand, and importables industries contract and therefore that optimal employment would rise in the production of export goods and fall in import production. Total employment and population may then rise or fall, and the outcome can be clarified only if further information about the nature of export and import production is specified. 
Consider an economy whose exportable goods are largely primary products, and whose import-competing industries are predominantly manufacturing. This model has features similar to those of the Australian economy. The manufactured goods would be liable to be produced under conditions of increasing returns to scale, whilst exportables would probably face decreasing returns because of the decreasing quality of resources available. Moreover, manufacturing probably employs a large percentage of the population. In these conditions an improvement in the terms of trade is likely for a variety of reasons to lower optimum population. It has been mentioned that there will be a rise in employment in exportables production and a fall in importables employment. However, the expansion of activity in the export-competing sector is liable to be inhibited somewhat by decreasing returns, and the rise in employment will be relatively small because of the low employment capacity of the sector. Because the relevant conditions in manufacturing are opposite to those in the primary sector, the employment contraction of secondary industries is liable to be large, so that the net result is a fall in optimum total population.

In connection with this it is interesting to note the relationship between the above argument and a case frequently made in favour of the Australian tariff. An article by Stolper and Samuelson (1941) came to the conclusion that for the type of economy we are considering a tariff would raise real wages. Because a tariff makes imports more expensive it will cause an increased demand for domestically produced manufactured goods. A rise in the demand for labour and hence a rise in its price will occur, because labour is relatively important in the production of such goods. Earlier the Brigden Commission on the Australian tariff (1929) had come to much the same conclusion. At that time the predominant opinion was that Australia was underpopulated, and they saw the tariff as a means of raising real wages and hence attracting more migrants. Although their conclusion about the effect of a tariff on real wages was later supported by the more rigorous analysis of Stolper and Samuelson, it is nevertheless true that others have argued that for the type of economy considered a tariff can have the opposite effect. It is not worthwhile going into these arguments here, but it should be noted that the analysis above gives a perspective on the subject of a different kind. A tariff would raise optimal employment in both the 
import-competing sector and the whole economy, for it worsens the effective terms of trade. There is, however, a cost, for worsened terms of trade mean lower real income (as we get less imports for our exports). A policy which justifies a tariff along these lines implies that the community judges that it would forego some per capita income for a higher population. In terms of the analysis of earlier sections the community attaches positive marginal utility to the absolute size of population.

The other sort of economy for which a clear cut answer seems possible is one for which exports are manufactured goods and imports are primary products. A rise in the terms of trade would encourage output of the industry with the greatest employment potential and so cause a rise in optimum population.

Subsequent analysis reverts to the assumption of a closed (notrade) economy.

\section{RESOURCES}

The need to take account of physical resources when studying various economic problems has long been recognised by economists. Indeed agricultural and other natural resource economists have of necessity given top priority to such considerations. However, it is not inconsistent to observe that for many years the emphasis of economic thought and writing has neglected resource issues. The constant returns to scale production function for which output depends solely on capital and labour inputs is perhaps the best example of this neglect. There are various reasons why this situation should have arisen, and among the most important is that incorporation of resources would add little to the understanding of many problems. Analysis of unemployment, inflation, and balance of payments disequilibria has occupied a large proportion of the profession since World War II and it would be difficult to argue that this work should have paid close attention to resources. As has been previously noted, in the area of the economics of growth the tendency has been to concentrate on capital accumulation, making assumptions which would rule out resource effects. One example of an exception to this tendency is the book Scarcity and Growth by Barnett and Morse (1963). It is worthwhile outlining their approach and main conclusions before presenting the analysis of this and subsequent sections. 
In the Ricardian system the restricted supply of resources and their declining quality would eventually lead to considerable shortages and restrictions on economic growth. Why, they ask, have manifestations of scarcity not appeared as strongly and definitely as one might expect from such theories? In the first place, it is argued, resources are not of a single kind so that often a substitute is available to offset declining supplies of some particular substance and, further, use of scrap (recycling) may in many cases be possible. More capital intensive production methods and changes in the composition of output may both work towards offsetting resource scarcity, although both may produce the opposite effect. Again resources are not as suggested in the Ricardian theory used in order of declining efficiency, partly because discoveries are continually being made, and also for the reason that population shifts have frequently rendered exploitation of certain resource reserves viable when their remoteness had previously curtailed their use. However, the main factor which they stress is technical progress, and it is interesting to quote their views.

Recognition of the possibility of technological progress clearly cuts the ground from under the concept of Malthusian scarcity. Resources can only be defined in terms of known technology. Half a century ago the air was for breathing and burning; now it is also a natural resource of the chemical industry. Two decades ago Vermont granite was only building and tombstone material; now it is a potential fuel, each ton of which has a usable energy content (uranuim) equal to 150 tons of coal. The notion of an absolute limit to natural resource availability is untenable when the definition of resources changes drastically and unpredictably over time. (p. 7)

Today, chemical processes and molecular transformation-not to say atomic - have greatly broadened the resource base. Such ubiquitous materials as sea water, clays, rocks, sands, and air have already become economic resources to some degree, and constitute major plateaus of virtually constant physical properties and-under the prodding of continual research and development-increasing economic quality. (pp. 9-10).

All this is not meant to imply that they recognise no limit to economic expansion, but rather they would seem to see little likelihood of a limit becoming effective in the near future. For population growth, however, a reservation is in order. 
Population growth constitutes a special problem. Living space on, or effectively near, the earth's surface is limited. But if living space is the ultimate limiting factor, the notion of Malthusian scarcity is no longer what it was a century and a half ago. The space limitation seems more likely to become manifest in crowded living conditions, a changed environment, an altered quality of life, than as increasing unit costs. For this reason, man may eventually undertake to limit his numbers, not by the operation of positive Malthusian checks but voluntarily, to avoid the qualitative effects of overcrowding-or, more immediately, in the less developed nations, to improve their prospects of increasing capital per head and the rate of growth of output relative to population. Malthusian scarcity would thus be transformed from a problem of subsistence, the lower limit of man's survival, to one concerned with the quality of life, with raising the upper limit to man's total welfare. (p. 12)

Whilst these arguments are persuasive, there are several factors which, in the light of current events, would seem to modify their position. The 1973-4 energy crisis, whether real or artificial, has cast doubts on optimistic assessments of energy availability. For future generations petroleum will be in short supply, and the availability of reasonable substitutes is still far from certain. Moreover, these assessments do not take account of the polluting effects of resource exploitation. Thus, for example, their view that sea water and air are, under the onslaught of modern technological methods of production and consumption, "major plateaus of virtually constant physical properties' is now open to serious doubt. Ten years after their publication it is not so easy to be convinced that resource abundance is still a safe assumption.

Thus there is little doubt that a way must be found to incorporate the effects of resource scarcity in the analysis of optimum population. To achieve this it is useful to ask what forms resources take, and how each can have direct and indirect effects on production, consumption and welfare. This discussion will not only have value for the present chapter, but will be useful later when attention is concentrated not on endpoints alone but on movements through time towards desired endpoints.

What are the substances which as natural resources enter production processes or are directly consumed and how can they be classified? As a defence against the complexity of the real world, economic theory usually abstracts from too much detail of this kind, but a proper incorporation of resources would seem to demand at 
least a general survey. A distinction which would seem to be of considerable value is that between exhaustible resources and nonexhaustible resources. Matter cannot be destroyed, but it can be scattered about considerably, chemical and physical changes can alter its character, and plant and animal life can be destroyed. Thus the dividing line between exhaustible and non-exhaustible resources is hard to draw, and the problem is further complicated by technical change which can require us to shift resources between these categories. Moreover, there are some resources which could be renewed at not too great a cost but which for some reason are not. Despite its arbitrary nature the following definition is still very useful. Renewable as contrasted to exhaustible resources are defined as those whose level and quality can be sustained at a 'reasonable' cost.

Many fuels such as coal, oil and uranium are non-renewable, and enter the production process after first undergoing a process of extraction. An exception is hydro-electric power which, provided equipment is maintained and siltation of dams prevented, would seem to be renewable. To the extent that some metals can be recycled they are renewable, but unless there is considerable technical change many would seem to fit better in the exhaustible category. The same is largely true of phosphate deposits, although to some extent they can be naturally renewed. Certain resources although potentially renewable are for practical purposes exhaustible if they are exploited. Thus the ancient redwood forests of California would take a very long time to replace, and the commercial exploitation of many types of animals could lead to their extinction.

Land for agricultural, forestry or grazing purposes must be classified as renewable. Like capital, land may be thought of as entering the production function as a stock which yields a flow of services over time. Moreover, as with other renewable resources there needs to be some recognition that unless appropriate action is taken its quality will depreciate. On the other hand, in some cases it will be possible to increase the available quantity and/or quality by diverting factors of production to this purpose. Both air and water are used in production and consumption and more often than not have been regarded as 'free' goods, where the freedom exercised was not only in usage but also in waste disposal. Water is available for the domestic uses of drinking, washing, and sewage disposal, for primary industry uses involving irrigation, stock consumption and 
for fisheries, for many secondary industry production processes, and in both sectors for waste disposal. Electricity generation has already been mentioned. Besides its uses for breathing and for combustion of many forms, the atmosphere is also used extensively for waste disposal notably from automobiles and industrial processes. Unlike land, air and water have not commonly been subject to a form of private ownership, so that whereas it is quite likely that renewal processes would be carried out with respect to land, clean air and water must usually be produced by public intervention where waste disposal exceeds the natural cleansing capacity of the environment.

All of this is fairly obvious, but it nevertheless provides the framework for economic models whose conclusions are not so straightforward and which have a more complex production structure than that of simple growth models. Before these can be investigated there is still more that must be said about resources.

Increasingly the question of resource use is becoming merged into the all embracing field of environmental management. This vast subject is the concern of many disciplines besides economics, and also includes problems of pollution, and of conservation of the natural flora and fauna. Public interest in this area has been aroused by an increasing flow of knowledge and information about such things as the connection between smog and automobile emissions, the effects of pesticides on human health and so forth. Ecologists, whose concern is with the interactions of living things amongst themselves and with their environment, have recently tended to put more emphasis on the links from man to his environment and from environment to man. Thus economists and ecologists are often found pronouncing on the same subject, although from different points of view. Provided each recognises the structure of the others' subject there need not be any substantial areas of difference between them. However, it would seem that the two groups are a long way from achieving an understanding. It is unnecessary to pursue the details of the resource management topic at great length here, but some brief remarks are in order.

In the first place the optimum time pattern of exploitation of exhaustible resources is essentially an economic question. Taking into account alternative uses, some of which may even be nonexhausting, a time pattern of use must be decided with reference to intertemporal considerations as well as various production con- 
straints. Further, it must be recognised that one possible outcome is that the resource is not subjected to exhausting exploitation at all.

As well as being aesthetically unwelcome, pollution can, of course, be a hazard to the health of human, animal and plant communities. Two categories of pollution would seem to be of relevance to our problem. In the first place there is pollution which would sooner or later have such destructive effects on human (and/or plant, and/or animal) life that they are to be avoided, if at all possible. An example is the dumping of mercury into rivers, lakes or the sea which not only has drastic effects on the local ecosystems, but which may also result in the poisoning of humans. Popular works by ecologists abound with many other examples, among which can be found the notion that energy consumption on the one hand may eventually melt the polar ice caps, and on the other lead to a new ice age. It is clear from such discussions that a great deal more scientific research must be done before these theories can be verified, but this does not mean that they should be ignored. This category of drastic pollution may have a variety of time profiles, two of which are as follows. One kind may produce totally unwanted effects if the accumulated production or consumption of some item in a given state of technique exceeds a certain figure (which may be very low), whilst another could result from the rate of production or consumption per period exceeding some figure. Policy makers must be supplied with data on these limits if they are to make appropriate adjustments. If the matter is still open to conjecture or the limit difficult to calculate, data in the form of the probability of drastic results at various levels would seem necessary. Depending on its attitude to risk society could use these data to prescribe limits.

By contrast with this drastic pollution, the other type which may be defined is such that (in the quantities that seem likely) its effects are irritating rather than profound. Nevertheless it creates disutility and/or adversely affects production. It is unlikely that zero levels of all kinds of such pollution would be a satisfactory or even possible solution. At the same time the level generated in an uncontrolled situation is probably higher than the social optimum. The benefits from pollution control must be weighed against the cost in terms of foregone production and consumption and of various control measures for an optimum trade-off to be decided.

So far no mention has been made of the use of resources for 
leisure purposes. Many leisure activities are priced and so enter into the market allocation system, but many others have aspects which are unpriced, or at least largely so. Mountains, sea shores, lakes, orchestras, sports facilities, museums, parks, zoos, etc., are public goods difficult to price yet nevertheless regarded as valuable by large sections of most communities. A public good is distinguished from a private good because its services are enjoyed jointly by all or many of the population. Because such resources are public goods their neglect and in some cases their pollution is common. The plants and animals which inhabit the natural environment are also public goods for which public opinion increasingly sees a need for protection and above all preservation of species threatened with extinction. An attempt will be made to incorporate the essentials of these aspects of resource management in the models which follow.

\section{OPTIMUM POPULATION AND RESOURCES}

Because long-run endpoints are the subject of study in this chapter, exhaustible resources will not be treated here. For simplicity the process of extraction of the services of resources is also subsumed in the production process. We shall, however, concentrate on resource renewal, but before doing so, it is useful to say something more about the per capita optimum solution studied previously.

How far will the use of renewable resources be taken and what will determine the rewards to resource owners (rents) at the optimum point? Suppose we have found the optimum population level. Given that level, it will pay to use resources (provided they are sufficiently plentiful) until they can no further contribute to raising output, that is until their marginal product is zero. This can be shown, as before, to yield a solution in which returns to scale are just exhausted. But an economy may not have sufficient resources to reach such a scale, and it will then be forced to accept a position in which the marginal product of resources is positive, and the whole stock of resources is being used. Then the economy will be operating in a range in which there are still increasing returns to scale.

These conclusions assume that the resource is of uniform quality. The Ricardian analysis treated the more realistic case of land which varied in quality, and in these circumstances all resources are not likely to be used at an optimum. We shall probably not in the future be growing wheat in Antarctica or on the moon. The better 
quality resources will, however, be exploited until their supplies are fully utilised, and they will be earning rent. Thus at the optimum population point income will be divided between labour and rents. Such results may seem disheartening to conservationists who would have a different type of claim on resources. Their desire to preserve some resources for their own sake and for recreation seems not to have a place here. However, this is because of the way the community's utility has been represented and there is nothing intrinsic in the approach of economics which has produced this conclusion. In addition to discussing renewal we shall introduce a conservation motive later in the discussion.

The economy is now supposed to have two main activities, namely production of goods and maintenance of the quantity and quality of resources. (We shall now revert to the case of a single resource.) Of course, some renewal will be carried out by private individuals, whilst some will be a matter for public action. Later we shall discuss the considerations which will decide when state action is warranted. Some, but not all available labour, capital and land will be used to produce goods. It is assumed that this productive process in a variety of ways draws down the supply of the resource. Production depletes resources in a direct way when it consumes their services, but it also reduces their quality indirectly because of the polluting effects of production processes. Renewal activities are required to offset these effects, and such activities, like production, require inputs of labour, capital and resources. There are some renewal processes which take place naturally if a resource is not disturbed. Thus preservation of a fishery requires catch and/or size limits, and the unharvested fish are a resource which is devoted to renewal activities.

It may help to write these relations in a symbolic form. If the subscript 1 is used for renewal and 2 for the production of goods the activity of the economy is depicted by

$$
\phi=\phi\left(\mathrm{N}_{2}, \mathrm{~K}_{2}, \mathrm{~L}_{2}\right) \text {, }
$$

the familiar production function, and

$$
\mathrm{L}=\mathrm{g}\left(\mathrm{N}_{1}, \mathrm{~K}_{1}, \mathrm{~L}_{1}, \mathrm{~N}_{2}, \mathrm{~K}_{2}, \mathrm{~L}_{2}\right)
$$

A dot over a variable indicates the rate of change of that magnitude. Here the change in resources (L) is taken in $(4 \cdot 5)$ to depend on the 
inputs into the process of goods production $\left(\mathrm{N}_{2}, \mathrm{~K}_{2}\right.$, and $\left.\mathrm{L}_{2}\right)$ which will reduce the resource stock, and the inputs into renewal $\left(\mathrm{N}_{1}, \mathrm{~K}_{1}\right.$ and $L_{1}$ ) which will build it up. ${ }^{7} A$ stationary position would require that renewal exactly offsets productive depletion so that $\dot{L}=0$. Note that the total resource stock employed in both activities is $\mathrm{L}=\mathrm{L}_{1}+\mathrm{L}_{2}$ (and that likewise $\mathrm{K}=\mathrm{K}_{1}+\mathrm{K}_{2}, \mathrm{~N}=\mathrm{N}_{1}+\mathrm{N}_{2}$ ).

To discuss the conditions implied by maximum output per head we need to define a variation on the marginal product concept. For each input the idea is the same, so that we may illustrate the notion with reference to labour. Suppose, say, 1000 more workers are added to society. Some of them (say 800 ) will be employed in the production of goods, but as this, by itself, will cause the resource stock to fall, some (200) also must be employed in renewal. The marginal product corrected for renewal (corrected marginal product) is the marginal product of labour in production multiplied by the ratio of the extra labour employed in production to the total labour force increase (in this case it will be 0.8 ). So, for a unit increase in labour employed in production we get a certain marginal product, but this must be corrected for the fact that part of the unit must be employed in renewal to keep the resource stock intact. An important implication of this is that the corrected marginal product can be zero now for two reasons. Firstly, there is the usual reason that it may be impossible to increase production, but, secondly, it may be zero because all of an increment in labour must be employed in renewal to prevent resource depletion.

From the conditions for optimum population we shall select only those of particular interest. ${ }^{8}$ The marginal product equals average product rule for labour is maintained as before, except that the corrected marginal product is the relevant concept, so that resource renewal is taken into account. Similarly, the corrected marginal product of capital is zero for this problem, and capital is employed in renewal up to the point at which it cannot contribute further to this process.

An interesting question about resources is whether they should be maintained at the maximum sustainable level, or allowed to decline somewhat and maintained at a lower level. There is no presumption

7 There are a variety of ways in which $(4 \cdot 5)$ could be formulated, but the assumptions made here capture the essence of the renewal process as much as any other formulation.

${ }^{8}$ For a full treatment see Pitchford (1974), Chapter 6. 
in the results so far that the maximum level will be sustained. The excess resources may be used up through depletion and pollution on the way to the endpoint or simply left idle. There is nothing in the system which puts a value on resources except that given by their usefulness in production or renewal.

It is often claimed by conservationists and others that if resource renewal and pollution problems were properly taken into account populations should be smaller than at present. Is this point valid when applied to optimum population? Actually it is found that there is no definite presumption either way so that optimum population may be larger or smaller when renewal is recognised. The reason for this is simply that, although the necessity for renewal suggests we are poorer than some may think, nevertheless renewal activities require labour. If such processes require large amounts of labour per unit activity, the economy may have a higher optimum population when they are properly recognised. What can be said for certain is that such recognition must mean that output per head is lower than before. The reason is that output per head employed in production can be no higher than before, but there will be heads employed in renewal who must share this output.

As well as the uses for resources so far mentioned, it should be recognised that conservationists and others also see a need to preserve natural resources for their own sake, and for recreation. Such a demand may be incorporated by writing the social utility function

(4.6) $\quad \mathrm{u}=\mathrm{u}\left(\frac{\phi}{\mathrm{N}}, \frac{\mathrm{L}_{s}}{\mathrm{~N}}\right)$

where $L_{3}$ are resources conserved for these purposes. This function will measure for the relevant circumstances how much of goods' output a community is willing to sacrifice to achieve a given increase in conserved resources.

A community whose objectives are expressed by $(4 \cdot 6)$ will always maintain its renewable resources at their maximum level provided a positive marginal utility is seen from conserved resources. This does not necessarily mean that there must be some resources which are used for conservation purposes. Consider moving a unit of resources from production to conservation. This action will be in line with the community's wishes only if the corrected marginal product of resources is less than the amount of consumption which the com- 
munity will sacrifice to conserve the extra unit. Otherwise all tesources will be used in production or renewal.

How are the results affected if the community has a positive discount rate, hence valuing present welfare more highly than future? This is not an easy question to analyse but one result can be easily suggested. A society with a very high rate of discount may have such a strong preference for present consumption that they are not prepared fully to make good all renewable resource depletion. This being so the optimum population as we have defined it is zero. By placing a large weight on present consumption, present generations may consume so much, and devote so little to maintaining resources, that the very existence of future generations becomes impossible. It should be emphasised that this is a completely rational outcome, the consequences being fully understood by the society involved when making its choices about consumption, investment, and resource renewal. Future generations may look back with regret to these earlier decisions, but look forward with the same consumption preferences as former generations. Of course, as poverty looms for their children, and as infant mortality becomes greater, it is possible, even probable, that the discount rate will be lowered, and that attempts to sustain resources sufficient to support continued human existence will be made. However, there is nothing in the nature of rational decision-making which ensures that optimum population must be positive. Such an outcome emerges from the interrelation of attitudes towards future generations (as expressed in the discount rate) with the costs of resource renewal.

In looking at these various conclusions it should be remembered that resource renewal need not be a task undertaken by the state. In many instances private firms will find it in their own interest to engage in renewal of a satisfactory nature. What then are the cases in which public intervention will be necessary and justifiable?

Firstly an important source of divergence between private and social action on resource exploitation can arise because private firms and resource owners have a higher discount rate than that relevant to public decisions. There are various reasons for this. First, it is clear that the society's holdings of resources is much more diverse than that of any private individual. Hence, given the existence of risk with respect to future profits, the private resource holder, if he is averse to risk, will want a higher rate of exploitation than would be 
socially desirable. Second, foreign firms may own domestic resources, and because of the uncertainty about the future status of their ownership and future tax rates on their earnings, and for other reasons may want a more rapid return on investment than domestically owned firms.

Then there is the category of resources over which it has been difficult or impossible to establish property rights. Such things as clean air and water are matters in which every individual has an interest. Yet it is almost impossible for individuals acting on their own to safeguard these interests. Public intervention with taxes on waste products and by the establishment of pollution control activities is needed to achieve socially optimal resource renewal. The processing and neutralisation of wastes is one area where there may well be significant increasing returns to scale, which can only he realised by centralised public action.

Finally, the conservation of resources for their intrinsic value and for recreation must also usually be a public function. Again the reason is that individuals acting in isolation will find it difficult or impossible to achieve their demands for these services.

It is now of interest to turn to a discussion of estimates that have been made of optimal population.

\section{ESTIMATES OF OPTIMUM POPULATION}

Forecasts of future population have been made for many countries. Not all such forecasts are aimed at estimating optimal or desirable population. Some, being only population projections of the type discussed in Chapter 2, will not be dealt with here, where for the most part some suggestion of desirability will be a feature of the estimates.

As may be expected the practical estimates do not go far towards using sophisticated theories or techniques. One reason for this is clearly the difficulty of applying such theories, whilst another certainly is related to the fact that estimates of the type discussed, whilst plentiful thirty or forty years ago, are not common since then. Later it will be of interest to speculate on the reasons for this. Although similar analyses could be made for other countries it is sufficient for purposes of illustration to limit the survey to estimates relating to Australia.

Methods by which estimates have been made vary widely. A 
common procedure is to give what amounts to a theoretical analysis of the problem (of greater or lesser rigour) and by applying this analysis in a general way to the actual situation to come up with an informed guess as to future desired population. A good example of this procedure is the chapter by Benham (1928) in The Peopling of Australia, entitled 'The Optimum Size of Population'.

As was noted earlier, Benham's optimum allows for appropriate adjustments of organisation and capital. In the course of a lucid and well reasoned analysis of optimum population he notes three factors which would suggest that Australia could support a larger population. The area at that time devoted to agriculture 'could be trebled without bringing under cultivation any land much less suitable than that at present under crop' (p. 256). Secondly, Australia's coal resources were regarded as very large, and lastly

a considerable increase of population would certainly enable fuller use to be made of existing railway lines, roads, bridges and of the 'fixed capital' mentioned above, concerned in supplying such utilities as water and sewerage, gas, electricity and harbour and dock facilities. (pp. 256-7)

He then goes on to observe:

In view of these considerations, I am inclined to think that the optimum is somewhere between 10 and 15 millions-about double the present numbers. The assumptions involved in this guess-for it can be nothing more should be remembered. It is assumed that the additional population is somehow supplied with additional capital; that changes in the economic organization rendered strongly advisable, if not imperative, by the increased numbers are made; that the present regional distribution of the population, with its concentration in the capital cities, continues; and that all other factors remain the same. (p. 257)

A quite different approach is contained in the analysis by Belz (1929). Using Pearl and Reed's theories he fits a logistic curve to the data available on Australia's population. This is not entirely a mechanistic forecast for it must be remembered (see Chapter 2) that the logistic curve was justified on the supposition that population figures would reflect the restrictions of the environment and so follow a logistic curve. The method gives a figure of 12.6 millions, the 12 million mark to be reached about the year 2000 .

A more detailed, but somewhat limited approach, forms the basis of many calculations of desirable population. Carr-Saunders (1936) uses data on the area of land in Australia with various average 
annual rainfalls. Each area is multiplied by the population density in the equivalent rainfall areas in those states of the United States lying west of the Mississippi. (Eastern states are excluded because of their high degree of industrialisation.) The sum over all rainfall areas gives a desired population (on the assumption that the United States densities are desirable). His figure for Australia turned out to be 29.6 millions. The same method was employed by Barkley (1928), and a figure of 'approximately thirty million people', is obtained 'for the population when Australia has attained the same relative stage of development and population as the western states (of the United States) had reached at the census of the year 1920' (p. 199).

Griffith Taylor $(1919,1937)$ wrote a good deal about the future settlement of Australia. His method for estimating desirable future population can be seen to be a more detailed and refined approach than that of Carr-Saunders. Whilst climate is important in arriving at the boundary of his 'zones of settlement', other environmental factors are also taken into account. Such zones 'may be classified as Industrial, Agricultural (temperate and tropical), Dense Pastoral (sheep and beef cattle), and Sparse Pastoral (sheep and beef cattle), and finally Desert areas' (1937: 402). The industrial zone, for instance, was regarded as depending upon supplies of coal, and the alpine region was deleted from the agricultural zone. Comparing population densities in these zones with those in similar regions in the United States and Europe he arrived at a figure of approximately 20 millions for population.

Another type of calculation made for Australia by Mullet and Wadham (1933) concerned the maximum number of people that could be fed at a given dietary level (in terms of a regimen of consumption of certain foodstuffs). Their procedure amounted to calculating the area of satisfactory land required per million of population, and comparing this with an estimate of the amount of such land available. Hence, the maximum population which could be fed was reached. 'The authors make no claim to forecast any figure with accuracy, so numerous are the approximations, but between forty and fifty millions seems practicable.' (1933: 208).

It is not suggested that this maximum is in any way a desirable level, nor need it imply a maximum if Australia were to become dependent on imports for food supply.

With the advantage of hindsight one can see the various errors 
and omissions for which these authors were responsible. The growth of secondary industry, the expansion of tertiary activities (such as education, health, transport), the development of hydroelectric power, the discovery of considerable mineral deposits, and the growth of technical knowledge are matters which would have been very difficult to predict with any accuracy. Less easy to excuse is the fact that apart from Benham, very little account is taken of economic considerations. In particular, the issue of whether markets would be available for the produce of the estimated population does not seem to have been much considered. Even though when the estimates were made Australia's economy was essentially based on primary products, a large proportion of the population still lived in the larger cities. In these circumstances it seems that excessive concentration on agricultural and pastoral industries was evident. If increasing returns to scale are mainly to be found in secondary industries the sorts of consideration arising from an economic optimum which have been discussed above are not likely to emerge if concentration is on the agricultural and pastoral sectors. Indeed none of the authors, except Benham, has looked for an optimum population, relying instead on comparisons which would put Australia on a par with the situation in some more developed area of the world. Perhaps this is because of the difficulty of obtaining an optimum estimate except by guesswork. Yet it is nevertheless true that the sorts of estimates which were prepared could be made now in much greater detail, and by attention to the additional matters mentioned, with a much more satisfactory basis.

Finally it should be noted that none of the authors attempted to follow the classical concept and estimate optimum population with capital held constant.

\section{FURTHER COMMENTS ON THE STATIONARY STATE}

There are a number of diverse points about the stationary state which do not fit easily into previous sections, but which should be made.

Firstly, like most such terms, 'stationary state' captures the essence of an idea, but does not necessarily suggest the complete picture. Thus a situation in which optimum population is attained need not be one wholly without change. Certainly technical progress is likely to be continually requiring adjustments, some of which will be of 
population. Moreover, changes in tastes have always been with us, and are liable to require adaptations of productive structure. The list could easily be continued.

Another point has to do with the fact that whilst our social objectives have specified per capita consumption, it has often turned out that we have been maximising per capita output. At an optimum population the difference between the two arises from the expenditures necessary to maintain the position. Thus depreciating capital must be replaced, resources must be renewed, and perhaps some expenditure may be necessary to hold population constant. Although we have allowed for some of these expenditures it should constantly be remembered that the ultimate aim is to maximise consumption per head.

One substantial difference between a stationary and a growing economy is seen in the claims which growth makes on output, and hence on what otherwise might be available for consumption. This idea can be made more explicit with the use of the concepts of capital widening and capital deepening. The former refers to the process of capital accumulation which in response to a rise in population is required to keep capital per head constant; to equip each new group of workers with capital equivalent to that already available to existing workers. Capital deepening occurs when the amount of capital per worker is raised. In an economy with population growth a good deal of output must go towards providing for capital widening. Not only must there be new productive capital for new workers, but there must be an increase in social overhead capital, such as schools, roads, transport services, and in private capital, particularly housing for the worker and his family. In a stationary situation such expenditures are not needed. A philosophy of 'growth for its own sake' could be extremely costly in these terms.

Opposition to the stationary state is liable to be strong. One group which has a vested interest in growth is resource holders. As population grows landowners will probably find their asset's price rises considerably, but in a stationary state this will not be so. It has been shown that the net return to capital at the optimum position is zero in the case in which no allowance for resources renewal is made. Private business interests would certainly not be keen on a stationary state in which, after paying management, and allowing for replacement of depreciating capital, net profit was zero. The supply 
of sufficient capital might well have to be encouraged by subsidies, or provided by other government action. Actually, when renewal of resources was taken into account, it was the marginal product of resources corrected for renewal which was required to be zero. It can be shown that this return must become zero because the economy is at a point at which all of an increment of capital must be devoted to renewal of resources if resources are not to decline. The zero return therefore occurs in the resource renewal activity, and for this reason such activity is unlikely to reach a socially optimal level under private control. Again, subsidies and/or some form of public ownership may be necessary to reach and sustain the optimum.

An apparent difficulty about a stationary economy could arise in the area of inflation control. To some extent it seems that inflation is due to a process whereby different income earning groups try to raise their real earnings. In so far as growth means increasing per capita output it is easier for any group's aspiration to be satisfied. In such matters as this it is difficult to distinguish the essence of such a process from the circumstances of the era in which it takes place. It may be that historians will record the 1950s and 1960s as a unique period not only of real, but also of imagined growth. Real growth there has been, but the promises of growth have been extravagant in the extreme. People have been taught to expect that rapidly rising living standards produced by technical change and capital accumulation are the norm. Their inflated expectations may have been partly responsible for the inflation which has been and still is most countries' experience. A more sober appreciation of the capacity for growth and higher per capita consumption may bring some lessening demands for higher incomes.

\section{REFERENCES}

Barkley, H. 1928. 'Climatic Factors Affecting the Distribution and Limits of the Population of Australia', in Phillips, P. D. and Wood, G. L. (eds.), The Peopling of Australia, Melbourne University Press, Melbourne.

Barnett, H. J. and Morse, C. 1963. Scarcity and Growth, Johns Hopkins Press, Baltimore.

Belz, M. H. 1929. 'Theories of Population and their Application to Australia', Economic Record. 
Benham, F. C. 1928. 'The Optimum Size of Population', in Phillips, P. D. and Wood, G. L. (eds.), The Peopling of Australia, Melbourne University Press, Melbourne.

Brigden, J. B. et al. 1929. The Australian Tariff-an Economic Enquiry, Melbourne University Press, Melbourne.

Cannan, E. 1888. Elementary Political Economy, London.

Carr-Saunders, A. M. 1931. Population, Oxford University Press, London, 1936. World Population, Clarendon Press, Oxford.

Dalton, H. 1928. 'The Theory of Population', Economica.

Gottlieb, M. 1945. 'The Theory of Optimum Population for a Closed Economy', Journal of Political Economy, December.

Mullet, H. A. and Wadham, S. M. 1933. 'Food Supply from the Point of View of Population', in Eggleston, F. W. et al. (eds.) The Peopling of Australia, 2nd Series, Melbourne University Press, Melbourne.

Penrose, E. F. 1934. Population Theories and their Application with Special Reference to Japan, Stanford University, California, Food Research Institute.

Pitchford, J. D. 1974. Population in Economic Growth, North-Holland, Amsterdam.

Robbins, L. 1927. 'The Optimum Theory of Population', in Gregory, T. E. and Dalton, H. (eds.), London Essays in Economics, Routledge, London.

Stolper, W. F. and Samuelson, P. A. 1941. 'Protection and Real Wages', Review of Economic Studies.

Taylor, Griffith 1919. Australia in its Physiographic and Economic Aspects, Clarendon Press, Oxford.

1937. Environment, Race, and Migration, University of Toronto Press, Toronto.

Wicksell, K. 1909. The Theory of Population, its Composition and Changes, Albert Bonniers Förlag, Stockholm. (Translated by the Australian National University Translation Unit, Canberra, A.C.T.) 


\section{Paths to Optimum Population}

Optimum population was defined, in the previous chapter, as a desired endpoint of a long-run growth process. But many economies may be far away from such an endpoint, and thus will be more concerned with the problem of deciding current growth policy. A way of informing ourselves about such problems is to study the optimal growth path. This should not be interpreted to imply that we shall necessarily be able to follow such a path. There are difficult problems of theory, of statistical estimation of relationships (such as production functions), and of implementation in the way of such an achievement. No doubt some second best policy which circumvents many of these difficulties will have to content us. Nevertheless, after studying optimal paths we should be better informed about the nature of the problems involved and better able to construct a second best policy.

Ideally, an optimal path would be a set of numbers showing at each point of time the required levels of population, capital, and other variables in which there may be interest. However, in trying to understand what constitutes an optimal policy it is necessary to go behind these numbers and ask two sorts of question. In the first place, it is of value to know what determines successive steps in an optimal path. That is, we wish to know the rules or criteria which characterise a path. With such rules we might, for instance, hope to look at any proposed policy and suggest how it compares with an optimal policy. Secondly, it is useful to know something about the time-profile of the path, usually referred to as the dynamics of the system's behaviour. For example, should an economy with less 
than optimal population raise its population level steadily to the optimum, or should it perhaps raise population beyond the optimum level and later reduce it? This last possibility is not necessarily unreasonable, for it may be a way of taking advantage of economies of scale so as to effect an increase in the capital stock. In what follows we shall look for both the criteria determining and the dynamic characteristics of the paths. It is usually not unduly difficult to discover optimal criteria, but may sometimes be much harder, or even impossible, to establish the dynamics of a path.

\section{POPULATION CONTROL}

The factors which may influence fertility and mortality were discussed in Chapter 3. It will be recalled that it was tentatively concluded that fertility may be negatively related to population density and education, and that per capita income did seem to affect mortality. One way of controlling population growth could be by the indirect method of influencing these determinants. Such an approach, however, must have strictly limited value. Raising education levels to reduce fertility, for instance, may achieve two goals (although there would probably be a time lag before fertility responded), but reducing output per head to increase mortality is, of course, absolutely unacceptable.

What are the more direct methods of changing the growth rate of population? An economy wishing to speed up population growth can choose to subsidise immigration. This seems a relatively straightforward means of achieving this result and, provided new citizens can be drawn from areas where wages are somewhat lower than domestically, is liable to be successful. The opposite policy of subsidising emigration is not so likely to work for a variety of obvious reasons.

There is some debate as to the success of raising birth subsidies as a means of increasing fertility, and of reducing them to lower fertility. Borrie (1970: 226) expresses doubts about their effectiveness which seem to be shared by other demographers.

The literature on birth control programs in less developed countries abounds with examples of schemes of fertility reduction. The dissemination of information on contraception, the provision of free or partly subsidised contraceptive devices, the legalisation of abortion, incentive schemes for vasectomies, and refraining from 
childbearing are only some of the methods tried. In China it is said that postponement of marriage and avoidance of intercourse outside marriage is encouraged. In some advanced countries considerable prominence has been given to environmental problems by the media, and some argue that this has led to choices implying smaller family size. It is too early to be able to assess the truth of this, but if it is well founded it would seem that publicity and propaganda are one way of influencing the birth rate.

Most of these methods of influencing population growth have one thing in common, that is they cost something. They are not free, and must be thought of as investment in population control, which has an economic cost. Investment in clinics or in persuasive advertising uses part of a country's production potential which could have been put to some other use. If it were not undertaken, that nation could have had more consumption goods and/or investment goods, and these foregone opportunities are the true cost of the programs.

There is a most important question which has yet to be answered. What justification is there for government interference to alter fertility patterns? In less developed countries, of course, lack of information about contraception, and the scarcity of private resources to limit family size must, in fact, provide grounds for such action. But in advanced countries most families will have the information and means to limit fertility. Presumably they choose their family size in accordance with their preferences, gaining satisfaction from their choice of spending income on bearing and bringing up children rather than on other things. One good reason for interference to reduce fertility is that in some countries government programs instituted for a variety of purposes may well have the effect of raising fertility, although this is not their direct aim. Taxation concessions for a taxpayer's children and subsidised medicine and schooling are examples. It would seem that the 'free choice' result could be achieved only if these influences are offset.

A fundamental argument for state involvement in fertility control is based on the notion that population growth is a public good (or bad). Defence is an activity often cited as an example of such a commodity. It confers services on all individuals in a society in the form of protection from attack, but nevertheless it would probably not be provided if it were left to individual rather than collective 
action. Population control has similar features. Suppose it were known that everyone would be better off if the average family size was reduced from say four to three children, in the sense that there would be a gain in per capita consumption which more than offset the loss in utility from having one fewer child. Although in this strong sense people would prefer the three child family it could be difficult or impossible to achieve this by individual voluntary action. The reason is that if an individual felt that everyone else was going to reduce their family size, it would be in his interest to choose the higher family size and have the benefit of increased consumption which everybody else's action will ensure. On the other hand if he thought that few if any would reduce their family size it would not pay him to do so, as this would have a small or even negligible impact on the economy and hence on his consumption. Collective action may well be necessary to achieve the result which all desire. What form collective action should take is a question beyond the scope of this work. For subsequent sections it is sufficient to note that it can be justified, and that it will have a real cost.

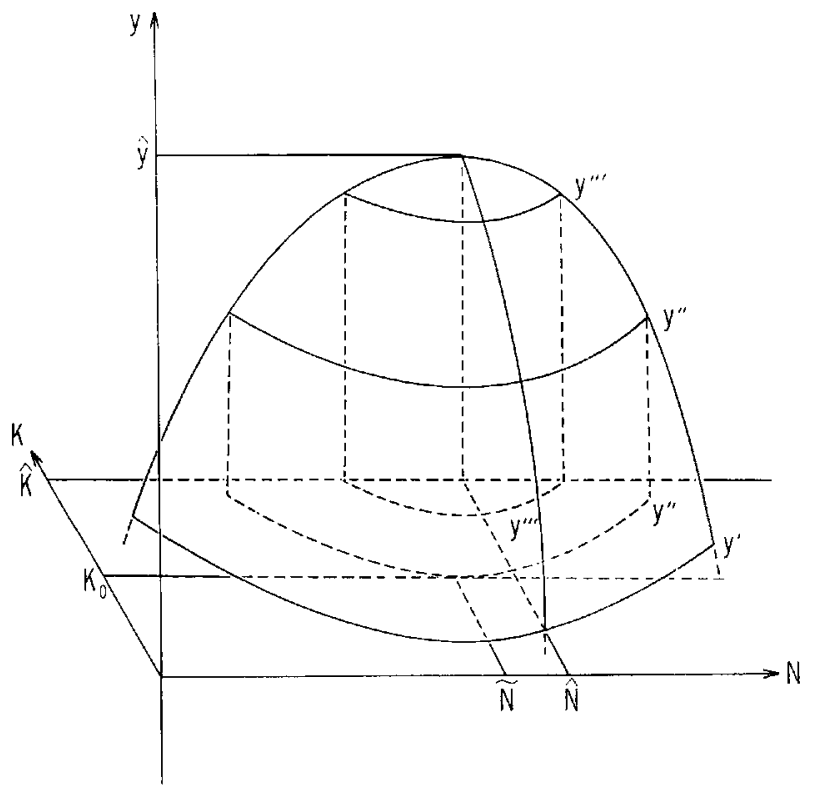

Figure $5 \cdot 1$ 


\section{A SIMPLE MODEL OF POPULATION CONTROL}

In this section we shall examine a drastically simplified model of long term economic change involving, amongst other things, expenditures to control population. A simple model has value in that it reveals the structure of the problem without getting involved in the complexities and details which more realism brings. Later on in the chapter more complex analysis will be attempted.

Production will be assumed to depend on inputs of labour and capital. Various features of this relationship have been depicted in earlier chapters, and it is useful here to introduce another aspect. A three-dimensional representation of the relation between output

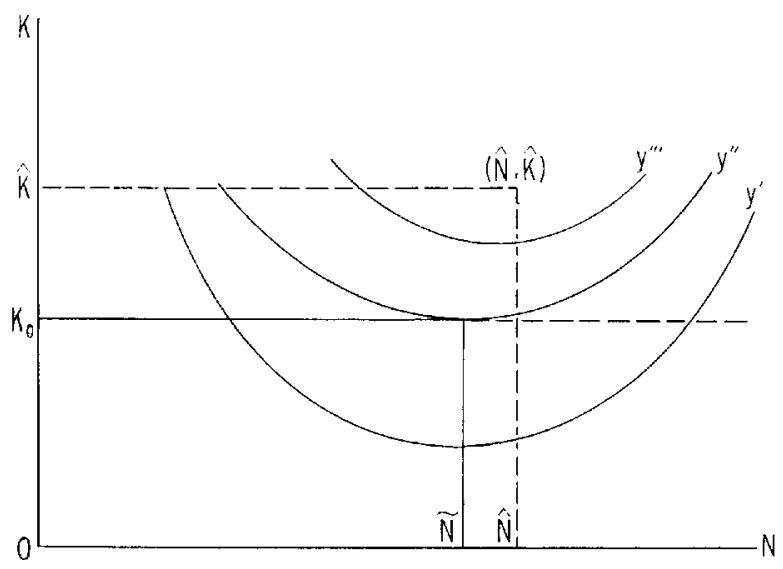

Figure $5 \cdot 2$

per head (y) and inputs of labour $(\mathrm{N})$ and capital $(\mathrm{K})$ is given in Figure $5 \cdot 1$. Output per head rises from $y^{\prime}$, to $y^{\prime \prime}$ to $y^{\prime \prime \prime}$ and reaches a maximum at $\hat{y}$. Such three-dimensional figures are difficult to work with, so we shall use a device common in other areas which enables us to work in two dimensions. Instead of drawing a picture of the average productivity hill we shall draw a map of its contours. Projecting the contours vertically downwards a contour map of the relationship is obtained, and it is this which is plotted in Figure $5 \cdot 2$. Every point on this graph represents a particular combination of the 
two productive inputs. ${ }^{1}$ The curve labelled $y^{\prime}$, for instance, joins all the points for which output per head is exactly at the level $y^{\prime}$. The shape of these contours, it will be shown, is consistent with our previous arguments about production relationships.

It is not difficult to establish why these curves have the properties illustrated. Recall that it has been argued (for instance, see Figure $(4 \cdot 1)$ that with a given capital stock output per head will first rise, then reach a maximum and later fall as employment is raised. This is all that is implied by the constructions here. Holding $\mathrm{K}$ constant at, say, $\mathrm{K}_{0}$ and increasing $\mathrm{N}$ from zero, low levels of output per head are first encountered. When $\mathrm{N}$ is sufficiently large $\mathrm{y}^{\prime}$ is reached, and further increases will eventually bring the economy to $\mathrm{y}^{\prime \prime}$ (larger than $y^{\prime}$ ). (This is the highest per capita output which society could reach and the population corresponding to this $(\tilde{\mathrm{N}})$ is what some would call optimum population (when capital is $\mathrm{K}_{0}$ ). (The irrelevance of this concept to any policy decisions is something which will be demonstrated in this section.) Increasing $N$ beyond $\tilde{N}$ will produce a fall in per capita output.

The 'top of the hill' is located at the point $(\hat{\mathrm{N}}, \hat{\mathrm{K}})$, and this is the point of optimum population (and capital stock). We shall suppose that initially the economy is at some other point and wishes to reach $(\hat{N}, \hat{\mathrm{K}})$. First, how does the economy move from its initial position to the desired endpoint? Capital can be accumulated through investment (I), that is, refraining from devoting all output to consumer goods, and this will be denoted symbolically by

(5.1) $\quad \dot{\mathrm{K}}=\mathbf{I}$

The dot over a variable must be read as 'rate of change in . . Equation $(5 \cdot 1)$ says that the rate of change in the capital stock is given by the amount of investment in new capital equipment.

Next we oversimplify the problem by assuming that in the absence of population control the population will be stationary. Thus population falls when action is taken to reduce births, but otherwise is constant. This unreal assumption is made to avoid a variety of complexities introduced by population growth. The model in the next section incorporates such growth. Moreover, we do not allow

1 The contours have not been continued into the region in which an economy has so much capital that the effect of adding an extra unit of capital is to reduce output (that is, its marginal product is negative). Such abundance does not seem likely to be reached. 
here for the age-structure of the population, so that all units of population are identical. (This has the drastic result of implying that an individual comes into being instantaneously able to produce and reproduce! Subsequently age-structure will be incorporated in the problem.) So population can be changed by appropriate expenditure to control fertility. It will be assumed that control can be applied to reduce births in the following way. Suppose it costs $\beta$ dollars to prevent one birth and that $\beta$ is constant whatever the level of expenditure on a population program. Then if a total amount of $\mathrm{J}$ dollars is spent on population control, the population will be reduced by an amount $\frac{J}{\beta}$. Hence, we may represent population movement by

$$
\dot{\mathrm{N}}=-\frac{\mathrm{J}}{\beta}
$$

Equation (5.2) states that if an amount $J$ is expended on population control the fall in population $(\dot{\mathrm{N}})$ will be $\frac{\mathrm{J}}{\beta}$.

Spending on investment or population control means that less will be available for consumption at any time. If the consumption per head is an amount $c$, total consumption ( $\mathrm{cN}$ ) is given by total output less investment and population control expenditure so that

$$
\mathrm{cN}=\phi(\mathrm{N}, \mathrm{K})-\mathrm{I}-\mathrm{J}
$$

Equations $(5 \cdot 1),(5 \cdot 2)$, and $(5 \cdot 3)$ tell us how the system will move when particular values of $I$ and $J$ are decided upon. It remains to be seen as to how these values should be chosen.

When studying optimum population the criterion for evaluating alternative actions was taken to be their effect on output per head, and this reflected a desire for maximum per capita consumption. Because a steady state was being analysed it was sufficient to examine per capita output in a single period only. To decide on an optimal path, however, we need some way of comparing per capita consumption at various points of time. A simple procedure is to add all the levels of consumption per head throughout the planning period and choose the path which maximises this sum as the optimal path. Deficiencies in such an approach will become apparent so that more acceptable criteria will be introduced in later sections. 
How long should the planning period be? It will be assumed that the period is long enough so that the economy can reach the optimum population and capital stock (shown as $(\hat{\mathrm{N}}, \hat{\mathrm{K}})$ in Figure $5 \cdot 2$ ). A shorter planning period would not be relevant to the problem.

Lastly it is necessary to specify that there is some minimum (c) below which consumption per head must not fall. Such a minimum may be a subsistence level, or may be a level which it is believed will preserve a particular type of society, or keep a particular party in office. For our purposes it is necessary to require this because without it the model may require zero consumption.

The problem is now sufficiently well specified for us to be able to extract the elements of a solution. An immediate consequence of our test of optimality is that along the optimal path consumption must be at its minimum level. This is easily seen. Suppose the planning period is of length $T$ and that the point $(\hat{\mathrm{N}}, \hat{\mathrm{K}})$ is reached after $T^{*}$ units of time (where $T^{*}$ is less than or equal to $T$ ). Now it pays to make $T^{*}$ as short as possible, for then $T-T^{*}$ periods can be spent at the point of maximum consumption per head. To move to $(\hat{\mathrm{N}}, \hat{\mathrm{K}})$ requires expenditure to change $\mathrm{N}$ and/or $\mathrm{K}$, and a condition that this will be accomplished in the shortest time is that consumption is at its lowest possible level (for then the remainder of income available for spending on investment or population control is at its highest level).

Thus the problem is partly solved already. Consumption per head is kept at its minimum level until the optimum population and capital stock is reached. Then it is raised to the maximum level. It has yet to be established as to how to divide expenditure (E) between investment and population control. The amount available for these purposes (rearranging $(5 \cdot 3)$, and substituting $c=c$ ) is

$$
\phi(\mathrm{N}, \mathrm{K})-\underline{\mathrm{c}} \mathrm{N}=\mathrm{E}
$$

Three possible types of policy are available:

A all of $E$ spent on population control;

$B$ all of $E$ spent on investment;

$\mathrm{C}$ expenditure divided between population control and investment. Take case $\mathrm{C}$ to start with. It will be established that if case $\mathrm{C}$ rules the following condition is satisfied:

$$
\beta \phi_{\mathbf{K}}+\phi_{\mathbf{N}}=\underline{\mathbf{c}}
$$


Condition $(5 \cdot 5)$ requires that the losses from having one fewer birth, and hence one fewer worker and consumer are just equated to the gain. There are two sources of loss which can be identified. First, if there is one fewer worker, total output is lower by an amount given by his marginal product $\left(\phi_{\mathrm{N}}\right)$. Society loses the amount he could have produced. Secondly, from equation $(5 \cdot 2)$ it can be seen that to reduce population by one person requires the expenditure of $\mathbf{J}=\beta$ units of output (for then $\dot{\mathrm{N}}=-1$ ). Now this amount could have been used to increase capital, so that the product of this extra capital $\left(\beta \phi_{\mathrm{K}}\right)$ is also lost. The gain arises from having one less consumer, so that an amount $\subseteq$ is released for other purposes.

Pursuing this theme further, if the losses are found to outweigh the gain $\left(\beta \phi_{\mathrm{K}}+\phi_{\mathrm{N}}>\mathrm{c}\right)$ population control will not be worthwhile, and all of $E$ will go towards building up capital (policy B). On the other hand if the gain is greater than the losses $\left(\beta \phi_{\mathrm{K}}+\phi_{\mathrm{N}}<\mathrm{c}\right)$ all of E should be devoted to population reduction (policy $A$ ).

This brings us another step closer to the solution of the problem, for the policy criteria have now been discovered. Considering the effect of reducing population below what it otherwise would have been by one person we conclude

$$
\left\{\begin{array}{l}
\text { loss }<\text { gain: reduce population (policy } \mathrm{A} ; \mathrm{J}=\mathrm{E} \text { ) } \\
\text { loss }>\text { gain: increase capital (policy } \mathrm{B} ; \mathrm{I}=\mathrm{E}) \\
\text { loss }=\text { gain: reduce population and increase capital (policy } \\
\mathrm{C} \text { ) }
\end{array}\right.
$$

Policy $\mathrm{C}$ will hold along a line in the $(\mathrm{N}, \mathrm{K})$ plane, and one possible shape and position for this line is shown in Figure 5.3. The line is labelled $\mathrm{C}$, and the arrows indicate the direction in which the economy will move. The line drawn has a negative slope, and this is consistent with policy $\mathrm{C}$, for as capital is increased, population is reduced. (Actually, the shape of the line along which $\beta \phi_{\mathrm{K}}+\phi_{\mathrm{N}}=\underline{\mathrm{c}}$ can only be determined after further information about production conditions is assumed. The simple case chosen illustrates the essence of the solution.) The marginal product of either input will depend on the amounts of both labour and capital with which the new unit of input will be working. Thus we can write

$$
\phi_{\mathrm{K}}=\phi_{\mathrm{K}}(\mathrm{N}, \mathrm{K}) \quad \phi_{\mathrm{N}}=\phi_{\mathrm{N}}(\mathrm{N}, \mathrm{K})
$$

and so express $(5 \cdot 5)$ in the form 


$$
\beta \phi_{\mathrm{K}}(\mathrm{N}, \mathrm{K})+\phi_{\mathrm{N}}(\mathrm{N}, \mathrm{K})=\mathrm{c}
$$

$(5 \cdot 8)$ is an equation specifying a relation between $\mathrm{K}$ and $\mathrm{N}$. Figure 5.3 illustrates the case in which for any $\mathrm{N}$ there is one (and only one) value of $K$.

Where do policies A and B operate? Imagine moving away from the $\mathrm{C}$ line in a north easterly direction, that is in a direction which will result in increasing both $\mathrm{K}$ and $\mathrm{N}$. The economy will become relatively well supplied with both capital and labour so the contribution of an additional unit of either will become smaller and smaller. In other words both the marginal products of capital and of labour fall. The losses from additional population control are less and the gain remains constant at $\underline{\mathrm{c}}$; hence policy $\mathrm{A}$ is relevant in this region.

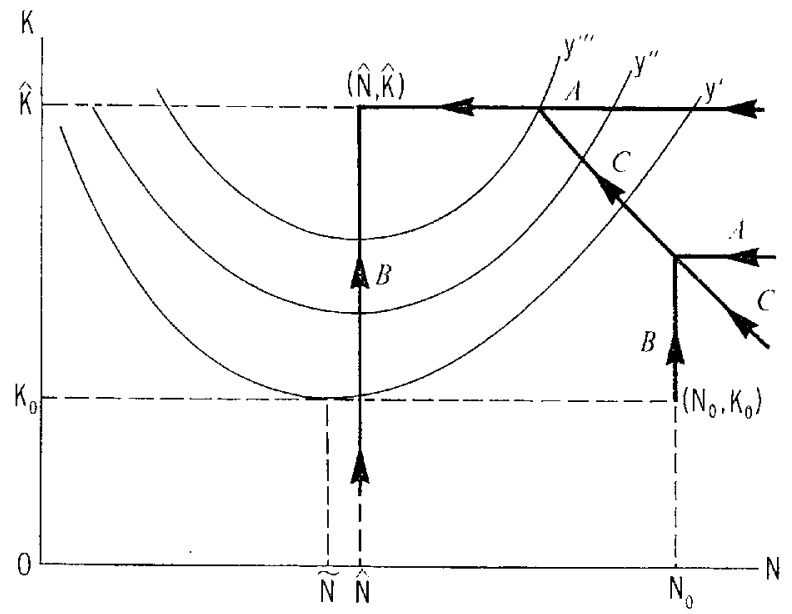

Figure $5 \cdot 3$

Reversing the argument it may be seen that to the left of the $C$ line $B$ becomes the required policy, for the smaller scale of the economy implies large marginal contributions of inputs.

The possible paths to optimum population from all possible starting points are illustrated in Figure 5.3. For instance, suppose initially population is at $\mathrm{N}_{0}$ and the capital stock is $\mathrm{K}_{0}$. Because the gains from population control are less than the costs it does not pay to have such a program. Instead all output above minimum consumption needs is invested and capital grows until the policy $\mathrm{C}$ line 
is reached. It is then optimal to spend both on reducing population as well as on investment following the $\mathrm{C}$ line to the point at which capital is at its target level $\hat{R}$. Thereafter population reduction becomes the exclusive policy until optimum population is reached.

Now let us look at the classical optimum population concept which was illustrated in Figure $5 \cdot 2$. When the economy is at $\left(\mathrm{N}_{0}, \mathrm{~K}_{0}\right)$ optimum population under this concept is $\tilde{\mathrm{N}}$. However, the optimal path is in no way influenced by this. Only when capital becomes $\hat{\mathrm{K}}$ does the classical optimum exert an influence on the economy, but then the classical optimum coincides with our long-run optimum $\hat{\mathrm{N}}$.

It must be stressed that the purpose of this model is mainly to illustrate the sorts of consideration involved and conclusions which may be reached. It does indicate the types of cost and gain which might be encountered in population control, and it does suggest that basing decisions on the sum of consumption expenditures may be undesirable as it leads to minimum consumption on the path to optimum population. Yet it must be complicated considerably before any sort of policy relevance can be attributed to it. In particular it should be recognised that population growth will usually be occurring, and that the consumption, production, reproduction, and mortality experience of the economy are closely related to the agestructure of population. These considerations are introduced in the next section.

\section{AGE-STRUCTURE AND POPULATION CONTROL}

Age-structure is important in population economics for two main reasons. The first is that interconnections between ages are of major significance in determining population movements. Thus the birth rate is critically dependent on the number of women in the childbearing ages 15-49, and the numbers in each age-group are, of course, the survivors from preceding age-groups. This type of model was analysed in Chapter 3, and it was noted there that eventually population would settle down to a steady rate of growth, or decline, or a constant level, depending on whether the net reproduction rate was greater than, less than, or equal to unity, respectively.

The other aspect of age-structure that will concern us is that different age-groups have differing economic functions. In particular the $0-14$ group contains young dependents who consume but do not 
produce. The work force is largely drawn from the 15-64 age group whilst those of age $65+$ are retired. This age-function aspect of population will be central to the subsequent analysis.

Following the procedure of Chapter 3 we shall work with a one sex (female) population. Fifteen-year age-groups capture most of the essence of the age-structure issues without introducing excessive detail. The years of dependence are taken to be 0-14 and 60-74 and hence working ages are 15-59. Population is supposed to be recorded each fifteen years. The relationships between the numbers of young dependents $\left(D_{t}\right)$, adults $\left(A(i)_{t}\right)$ and old dependents $\left(R_{t}\right)$ are given by

$$
\left\{\begin{array}{l}
A(1)_{t}=q_{1} D_{t-1} \\
A(2)_{t}=q_{2} D_{t-2} \\
A(3)_{t}=q_{3} D_{t-3} \\
R_{t}=q_{4} D_{t-4}
\end{array}\right.
$$

$A(1)_{t}$ is number of individuals in the $15-29$ group at time $t$. Similarly, $A(2)_{t}$ and $A(3)_{t}$ are the numbers in the 30-44 and $45-59$ groups. Consider the number of dependents who were in the 0-15 age-group fifteen years earlier $\left(D_{t-1}\right)$. It is assumed that a constant proportion of these $\left(\mathrm{q}_{1}\right)$ will survive to the 15-29 age-group fifteen years later. This is what is implied by the first equation of $(5 \cdot 9)$. The second and third equations refer to the survival patterns from the dependents of 30-45 years earlier respectively. Those in the retired category at time $t\left(R_{t}\right)$ (here taken to be $60+$ ) will be the proportion $\mathrm{q}_{4}$ surviving from the dependents of 60 years earlier.

The work force at time $t\left(A_{t}\right)$ is given by

$$
A_{t}=A(1)_{t}+A(2)_{t}+A(3)_{t}
$$

To complete the population part of the model it is necessary to specify how births are determined. The basic assumption will be that the population is subject to maternity rates which (apart from population control) are fixed for all ages in the range 15-44, and are zero outside these limits. At time $t$ the groups subject to these rates are $A(1)_{t}$ and $A(2)_{t}$. As the next fifteen-year period elapses the women in the 30-44 group will move to higher ages and will by the time $t+1$ all be out of the reproductive span. Moreover some who are dependents will move into the 15-29 group and at $t+1$ all will be potential parents. Hence at time $t+1$ the number of dependents will be 


$$
\mathrm{D}_{\mathrm{t}+1}=\alpha_{0} \mathrm{D}_{\mathrm{t}}+\alpha_{1} \mathrm{~A}(1)_{\mathrm{t}}+\alpha_{2} \mathrm{~A}(2)_{\mathrm{t}}
$$

where $\alpha_{0}, \alpha_{1}$ and $\alpha_{2}$ are constants. (Most demography textbooks will contain the details of this derivation for those who would like to go into it more fully. ${ }^{2}$ )

The rate of production and of the various categories of expenditure as well as the capital stock are assumed to be observed at time $t$ and other points of time separated by fifteen-year intervals. Expenditure on population control at time $t\left(J_{t}\right)$ is taken to affect births through the subsequent period and hence to influence the number of dependents at $t+1$. Hence allowing for population control of the same form as in the previous section, we may write

$$
D_{t+1}=\alpha_{0} D_{t}+\alpha_{1} A(1)_{t}+\alpha_{2} A(2)_{t}-\frac{J_{t}}{\beta}
$$

Production at time $t$ is taken to depend on inputs of labour $A(t)$ and of capital $\mathrm{K}_{\mathrm{t}}$, so that

$$
\phi_{t}=\phi\left(A_{t}, K_{t}\right)
$$

and the allocation of output to various expenditure items is given by

$$
\phi\left(A_{t}, K_{t}\right)=c_{t} A_{t}+v D_{t}+b R_{t}+J_{t}+I_{t}
$$

Here $c_{t}$ is consumption per head of workers, $v$ is consumption per head of young dependents, and $b$ consumption per head of retired persons. $(5 \cdot 14)$ states that output is consumed by each of the groups in society, and used for population control and/or investment.

When a set of values of $c_{t}, v, b, J_{t}$ and $I_{t}$ are decided on the population and capital stock for the next period will be determined. Repeating this process generates a time path for the system.

The test we used in the previous section for whether one path was 'better' than another was to ask which path had the greater value of accumulated per capita consumption. This test was seen to have the shortcoming that it induced concentration on maximising the speed of movement of the system to the detriment of per capita consumption. Here we shall use a more satisfactory test which we shall proceed to build up, based on adding socially valued per capita consumption. The reason for this should be clear, for it was observed in Chapter 4 that the assumption of diminishing marginal utility

2 See, for instance, Barclay (1958). 
places relatively greater weight on increments of consumption when a country is relatively poor.

First it will be assumed that the consumption per head of each dependent group ( $\mathrm{v}$ and $\mathrm{b}$ ) are constants. This may seem to be hard on dependents, but if each dependent is regarded as attached to a worker's family these may be regarded as minimum figures. Only the average consumption of workers $\left(\mathrm{c}_{t}\right)$ enters the utility function, and adding these through time gives

$$
\mathrm{u}\left(\mathrm{c}_{0}\right)+\mathrm{u}\left(\mathrm{c}_{1}\right)+\ldots+\mathrm{u}\left(\mathrm{c}_{\mathrm{t}}\right)+\ldots
$$

with the dots indicating that terms are to be inserted, in their proper sequence.

Let us make yet another adaptation and introduce discounting into our assessment. To do this it is necessary to formulate some simple propositions about discounting formulac. Suppose a sum of money, say $\$ X$ is invested for $T$ periods at a rate $r$. If interest is added at the end of each period it is straightforward to calculate that after $T$ periods the sum will have accumulated $t^{3}$

$(5 \cdot 16) \quad \mathrm{Y}=\mathrm{X}(1+\mathrm{r})^{\mathrm{T}}$

Now turn the sum around and ask what amount will need to be invested at rate $\mathrm{r}$ to accumulate to $\mathrm{Y}$ after $\mathrm{T}$ periods? From $(5 \cdot 16)$ the answer is

$$
X=Y \frac{1}{(1+r)^{\mathrm{T}}}=Y\left(\frac{1}{1+r}\right)^{T}
$$

$\mathrm{X}$ is called the present value of $\mathrm{Y}$ or the discounted value of $\mathrm{Y}$. Thus if we wish to discount future utilities at a rate $\rho$, a typical term of $(5 \cdot 15)$, say that at time $t$, must be multiplied by $\left(\frac{1}{1+\rho}\right)^{t}$ so as appropriately to reduce its value. Note that as $\rho$ is positive $\frac{1}{1+\rho}$ must be less than unity. It is useful to define a discount factor $\delta=\frac{1}{1+\rho}$ which measures the proportion by which at any time the utility of next period will be undervalued compared with current utility.

- To verify $(5 \cdot 16)$ work it out for $T=2$, and $T=3$, 
Hence the optimal path will be the one which gives the largest value of

$$
\mathrm{u}\left(\mathrm{c}_{0}\right)+\mathrm{u}\left(\mathrm{c}_{1}\right) \delta+\mathrm{u}\left(\mathrm{c}_{2}\right) \delta^{2}+\ldots+\mathrm{u}\left(\mathrm{c}_{\mathrm{t}}\right) \delta^{\mathrm{t}}+\ldots
$$

As yet the horizon over which the plan will stretch has not been specified. There is considerable value in assuming that the planning period is infinite. First, if we assume that the end of the world is a very long way off, an infinite horizon will be a good approximation to this proposition. Secondly, with an infinite horizon we can leave the values to which population and capital will tend to be discovered as part of the overall solution, rather than specify in advance what they should be. This will serve as a check on our earlier procedure of requiring the path to lead us to optimum population. Thus the dots in (5.18) may be taken to imply an infinite sequence of terms.

We may now proceed to the solution of the problem, and shall first investigate the nature of the criterion which an optimal path should obey. The steps in deriving this result will not be covered, but it will be seen that the result has considerable intuitive appeal. Consider the effects of expenditure at time 0 which reduces the number of young dependents by one thousand. The persons concerned could have lived for up to seventy-five years so the effects of this policy must be traced through the whole age-span. In each period there will be costs and benefits from this change. For the moment we shall not inquire what these are, but shall concern ourselves only with the ways they should be compared with each other. This information is expressed in

$$
\begin{aligned}
& u^{\prime}\left(c_{0}\right) \frac{W_{0}}{A_{0}}+\delta u^{\prime}\left(c_{1}\right) \frac{W_{1}}{A_{1}}+\delta^{2} u^{\prime}\left(c_{2}\right) \frac{W_{2}}{A_{2}}+\delta^{3} u^{\prime}\left(c_{3}\right) \frac{W_{3}}{A_{3}}+ \\
& \delta^{4} u^{\prime}\left(c_{4}\right) \frac{W_{4}}{A_{4}}+\delta^{5} u^{\prime}\left(c_{5}\right) \frac{W_{5}}{A_{5}}
\end{aligned}
$$

The net cost (that is, costs minus benefits) arising at any time $t$ is $\mathrm{w}_{\mathrm{t}}$. This magnitude is appropriately discounted (multiplied by $\delta^{\mathrm{t}}$ ), valued in terms of utility (multiplied by marginal utility $u^{\prime}\left(c_{t}\right)$ ) and reduced to per capita terms (divided by $\left.A_{t}\right) .\left(u^{\prime}\left(c_{t}\right)\right.$ must be read as: the marginal utility of an increment in consumption when consumption is at the level $c_{t}$ at time t.) All the net costs must then be added to determine whether population control is worthwhile. The reason for multiplying by marginal utility is that this magnitude 
measures the value of marginal cost (or gain), so that $w_{t}\left(u^{\prime}\left(c_{t}\right)\right.$ ) measures the value of $w_{t}$ units of marginal cost (or gain).

Now examine the net costs. These will be shown to be:

$$
\left\{\begin{array}{l}
\mathrm{w}_{0}=\beta \times 1000 \\
\mathrm{w}_{1}=-\left(\mathrm{v}+\beta \alpha_{0}\right) \times 1000 \\
\mathrm{w}_{2}=\mathrm{q}_{1} \times\left[\phi_{\mathrm{A}}(2)-\beta \alpha_{1}-\mathrm{c}_{2}\right] \times 1000 \\
\mathrm{w}_{3}=\mathrm{q}_{2} \times\left[\phi_{\mathrm{A}}(3)-\beta \alpha_{2}-\mathrm{c}_{3}\right] \times 1000 \\
\mathrm{w}_{4}=\mathrm{q}_{3} \times\left[\phi_{\mathrm{A}}(4)-\mathrm{c}_{4}\right] \times 1000 \\
\mathrm{w}_{5}=-\mathrm{q}_{4} \times \mathrm{b} \times 1000
\end{array}\right.
$$

At time 0 the only effect of the policy is that it costs $\beta \times 1000$ to prevent 1000 dependents next period. By period 1 there are 1000 less dependents and so a benefit of the program has been that consumption of dependents is less by $v \times 1000$. The other item of benefit in period 1 is more subtle. If the 1000 had been dependents at time 1 they would have reproduced so that there would be $a_{0} \times 1000$ more dependents by time 2 . It would have cost an amount $\beta \times \alpha_{0} \times$ 1000 to have prevented these dependents of the original 1000 . It must be regarded as a gain to the program that this expenditure need not be made.

By time 2 , that is thirty years after the original expenditure to control population, the survivors of the 1000 would have become adults. Their potential extra product $\phi_{\mathrm{A}}(2)$ must be counted as a loss, but a gain arises because they would not be consuming $\left(\mathrm{c}_{2}\right)$. The other source of gain $\left(\beta \alpha_{1}\right)$ is of exactly the same type as that discussed for period 1. A proportion $q_{1}$ only of the original 1000 would have survived so that these gains and losses must be reduced by multiplying by $\mathrm{q}_{1}$. For time 3 the gains and losses are of precisely the same form as for time 2 .

At time 4, all the survivors of the original 1000 would have moved out of the reproductive span. Hence, the only gain is $c_{4}$ and the loss is $\phi_{\mathrm{A}}(4)$. Finally, when retirement age would have been reached there is only the gain through consumption saved (b) to be considered.

We have remarked that the dynamic behaviour of this system is difficult to generalise about. However, we can determine what its eventual steady state will be, if it indeed settles down to such a state. The formula looks a little complicated with discounting so we shall quote it for the case in which the discount rate is zero. Using the fact 
that population, output, the work force, etc., will all be constant in a steady state, we get ${ }^{4}$

$$
\phi_{A}-\frac{(\phi-I)}{A}=0
$$

Now investment in a steady state must be just at replacement level. Hence $\phi-I$ is output net of replacement investment, and it was this net output concept with which we were working in earlier chapters. Thus in the special case in which the discount rate is zero we get exactly the same condition for optimum population as in Chapter 2. A positive discount rate would, of course, have given a different condition.

How can the information in $(5 \cdot 19)$ be used to construct an optimal path? Suppose a program of development including population control is postulated and the values of population by various ages, capital, output, etc., are substituted into our equations so that $(5 \cdot 19)$ can be calculated. If the value produced by this calculation is positive it suggests that a marginal net loss is involved in the population control program and hence it should be reduced. On the other hand if there is a negative value this means that the program involves a marginal net gain and so the program should be expanded. It should be increased until either all available income is spent on population control, or the marginal net gain is zero. We will then be on the optimal path.

Actually, the preceding sentences make the solution problem seem much simpler than it really is. There will be a criterion expression such as $(5 \cdot 19)$, for every point of time, that is for an infinite number of points, and as well there will be another criterion expression (not introduced here) for capital calculations. All values are interconnected, so that we must solve simultaneously for all of them. It is unfortunate but true that even at the level of simplification used here, the solution of these problems can be exceedingly complex. However, it is sometimes possible, when all the relevant numbers are specified, to find a method of computer simulation which will trace out a path for us. Apart from this possibility, the value of the foregoing analysis lies in the fact that it informs us of the sorts of considerations relevant to population and economic growth. There

4 To deduce this the reader must put together all the information previously specified for the problem, assume that all variables are at constant levels, and take $\delta$ to be unity. 
are those who would use rules of thumb to decide these matters. This discussion may help them to decide on better rules, and also it should help us to be sceptical of and perhaps constructively to criticise such rules.

\section{EXHAUSTIBLE RESOURCES}

Suppose a single resource is held in quantity $X(t)$ at time $t$. It is illuminating to abstract for the moment from the population problem and ask how we should in given circumstances exploit this resource. Suppose $\mathrm{E}(\mathrm{t})$ is the rate of exhaustion of the resource then the rate of change of $X(t)$ is given by

$(5 \cdot 22) \quad \dot{X}(t)=-E(t)$

Assume that the resource is used as an input to make consumer goods so that (omitting capital and labour, as they are to be held constant) the production function is

$$
\phi=\phi(\mathrm{E})
$$

Suppose we wished to get as much output as possible from this resource stock, how would we exploit it through time, and how long would it last?

The answer is straightforward. To get the maximum output from the total stock, each unit of resource used must yield the greatest output. Hence we must seek to maximise the output per unit of resource input (or $\frac{\phi(E)}{E}$ ). From Figure 5.4 it is clear that this requires

$$
\phi_{\mathrm{E}}=\frac{\phi}{\mathrm{E}}
$$

that is the optimum rate of exploitation ( $\hat{\mathrm{E}})$ is the one at which the average and marginal products of resources are equated. The time taken to exhaust the resource will be found from

$$
\hat{\mathrm{E}} \times \mathrm{T}=\mathrm{X}
$$

How can these results be used to inform us about optimum population? To say how population, resource use and capital accumula5 Vousden (1973) has examined the pure resource allocation problem, whilst the relationship between population growth and resource use is explored in Pitchford (1974). 
tion should vary in an optimal growth process would require a dynamic analysis of the type attempted in the previous section, and this will not be attempted here. However, certain conclusions about optimum population can be deduced without such elaborate procedures. The essence of the results is that at different times there may be two distinct optimum population levels. One involves exploitation of the exhaustible resource, and the other occurs after the resource is exhausted. If the resource is initially plentiful there may be sufficient time to attain an optimum population based on the

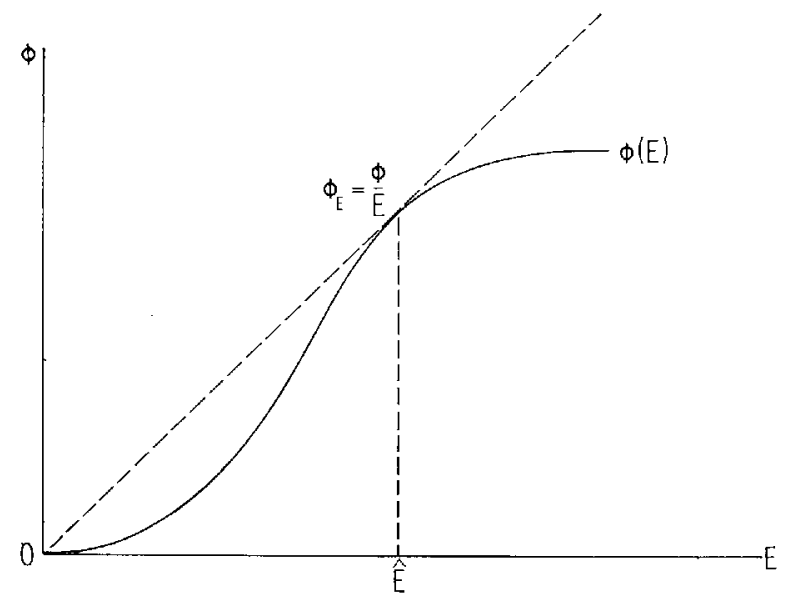

Figure $5 \cdot 4$

use of the resource. This state will involve a greater per capita output than the second, where an optimum must be based on renewable resources only. Suppose, that when resources are exhausted the optimum population state produces an output $\hat{\phi}$. This, then is the minimum which can be attained in the long run when there are resources still available. Hence, we might expect that in the plentiful resource phase we may wish to use resources so as to maximise $\frac{(\phi-\hat{\phi})}{\mathrm{E}}$, that is to get the most surplus above the alternative steady state situation. Figure $5 \cdot 5$ illustrates this optimum.

At the point $\tilde{\mathrm{E}}$ it can be seen that $\frac{(\phi-\hat{\phi})}{\mathrm{E}}$ is a maximum, and that 


$$
\phi_{\mathrm{E}}=\frac{\phi-\hat{\phi}}{\mathrm{E}}
$$

Hence we can determine an optimum population level based on exploitation of (relatively plentiful) resources. Further investigation reveals that there is no intrinsic reason why the population level so determined will be higher in such a regime, than in one where resources are exhausted. ${ }^{6}$ Only when relatively detailed information about the economy is known can this question be decided. If $i t$ were

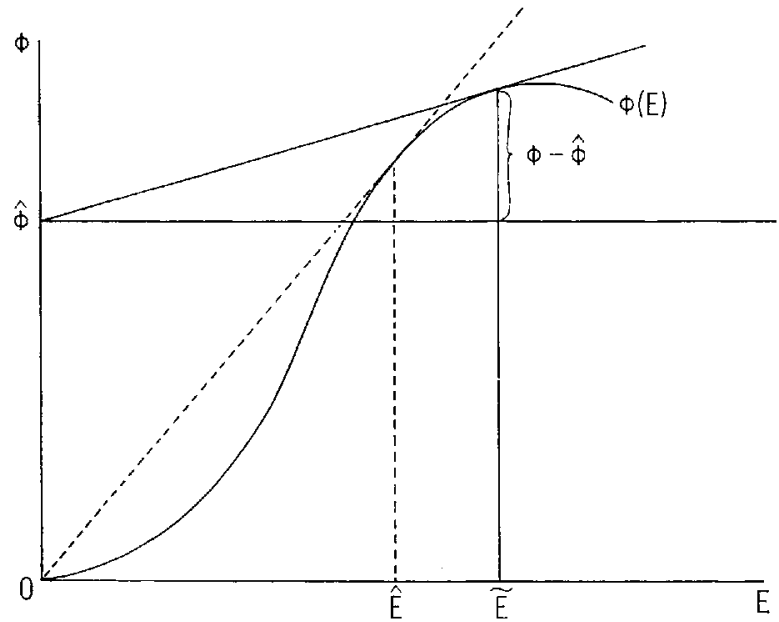

Figure $5 \cdot 5$

found that the two optimum populations were very different, it is obvious from the analysis of the previous section, that it would be necessary to plan the transition well in advance of resource depletion.

However, it must be remembered that when comparing these two population levels we are looking at optimum situations. A very different picture could be discovered if actual populations are compared, or if the level the actual population reaches when exhaustible resources are available is compared with that which would be optimal when they are depleted. If the exploitation of exhaustible resources is a stimulus to a high rate of population growth it seems entirely reasonable to suppose that their exhaustion might be associated with a population level in excess of the appropriate ${ }^{B}$ See Pitchford (1974), Chapter 8. 
optimum. Of course, drastic resource scarcity is unlikely to appear suddenly without notice. It would be surprising if such an event was not preceded by a period of rising rents to resource holders and of rising resource prices which would ration the scarcities, and encourage substitution of other resources of both known type and use and, through technical change, of new uses and new resources. The chief difficulty in this process would seem to stem from population. If population reduction was required it is doubtful whether the warning signals would be early or powerful enough to effect a smooth adjustment. The time lag in the response of population built into the system through age-structure effects may be quite long. If population is also somewhat insensitive to economic conditions it could well turn out to be above an optimum level for some time.

Mention has previously been made of Wrigley's (1967) article on the supply of raw materials in the Industrial Revolution. Before this revolution, he argues, expansion of industrial production was limited by its dependence on wood as a source of fuel. The English economy was in a situation where any expansion of industry required more land to be devoted to forests, but this competed with agricultural and pastoral land requirements. Discovery of ways of replacing wood with coal meant a lifting of the limits to growth implied by the restricted land supply.

In the very long run the mineral supply problem is insoluble in a sense which is not true of organic raw materials, since every mine is a wasting asset. It cannot be made to give a sustained yield in the way which is possible with a forest or a farm. A forest can yield indefinitely: a mine cannot. Nevertheless, in any but the very long run the difficulty of obtaining a large increase in supply is less pronounced with mineral raw materials. (p. 99)

$\mathrm{He}$ cites Jevons as asserting that the greatest single factor in the industrial wealth of a nation is its supply of coal, and goes on to quote him as follows:

Coal, in truth, stands not beside but entirely above all other commodities. It is the material energy of the country-the universal aid-the factor in everything we do. With coal almost any feat is possible or easy; without it we are thrown back into the laborious poverty of early times. (p.120n.)

There is no doubt that exhaustible resources are basic to the prosperity of many economies today. The question of how long 
before they are exhausted remains to be answered, and is of critical concern to economic and population planning. Ultimately some form of reverse industrial revolution must be achieved with reliance on a sustainable flow of raw materials being established. Once this is recognised it becomes clear that careful and extensive data collection and examination is necessary so as to anticipate possible shortages. In this connection it is appropriate to end this section with a final quote from Wrigley:

It is interesting to note that Jevons's main concern was that supplies of coal must soon run short in Britain; that mineral raw materials, being exhaustible, were a dangerous basis of national wealth and power. (p. 120)

\section{CONCLUDING REMARKS}

It is always useful to conclude a work such as this by referring to problems not yet investigated, and complications not yet introduced. Not only does this serve as a caution to the reader, but it also helps to remind the author of where he thinks future investigations should lie. The first part of these remarks is devoted to this exercise.

The early attempts to estimate optimum population for Australia have been criticised for not foreseeing technical change. It may seem surprising then that I have not given much emphasis to the effects of such change in previous discussion. One reason for this is that in some cases technical change has not been the unmixed blessing which many assume it to be. The main reason, however, is of a different nature, and applies to many if not most aspects of the subject in varying degrees. Technical change over anything but a short period is unlikely to be capable of being forecast with a high degree of certainty. How should planning be affected by such uncertainty? Clearly the outcome must depend on the community's attitude to risk, that is, whether it is risk averse or risk preferring. Given our uncertainty about technical change it would seem to be misleading to analyse the problem in any other context. Another reason for failing properly to estimate optimum population is that resources, especially minerals, have continually been discovered, making earlier forecasts of their supplies erroneous. Again it is difficult to see how to allow for this in a framework which does not recognise uncertainty.

The models in this chapter were deliberately simple. If they were 
to be further complicated, one of the first things to do would be to allow for the utility (or disutility) arising from children. To some extent people have children because they want to, so that deviations from their planned family size will be made only reluctantly. This feature must modify the cost-benefit relationship set out. Moreover the models made no attempt to include an explanation of induced fertility change (except through population control). This was deliberate as I did not feel sufficiently convinced by any of the theories surveyed in Chapter 3. Yet it would be an interesting exercise to make fertility dependent on output per head, say, as well as on population control expenditure. And, of course, further work needs to be done on the way in which population control expenditure affects fertility.

Can the concepts which have been developed be used to obtain estimates of optimum population? This is an open question, for to my knowledge no thorough attempts to apply them have been made. It is frequently the case in economics that the data relevant to a particular problem are either not collected, or are impossible to collect. For instance, we cannot know what future generations' preferences will be, and hence we lack precise information on their utility functions and discount rates. On the other hand calculations can be made on the basis of various utility assumptions, leaving the task of choosing between them to the policy-makers. A good deal of work has been done on estimating production functions both for individual industries and for output as a whole. However, these studies have often not paid much attention to problems of scale economies and diseconomies. A study of optimum population would also need to look at probable future improvements in technology, and probable changes in the terms of trade.

It should be possible to make some quantification of resource constraints. These set limits in which optimum population would lie and so help to narrow down the problem. For renewable resources the question of their maintenance would require investigation, whilst exhaustible resources should be examined with respect to their depletion and the existence of substitutes. In any practical study a set of problems which we have not yet allowed for would have to be tackled. This includes questions of the size of cities and the location of new growth centres. To some extent the pattern of industries will determine the rural-urban composition of the population, but there 
are additional problems which arise out of attitudes towards urban living, and the demands of cities for transport, water, sewage treatment and so forth, which must be taken into account. It is unlikely that all these facets can be estimated and put together in the way the theory requires. On the other hand, the theory should enable us to see more clearly the elements of the problem, and to come to a more informed guess about optimum population than could be made without it.

Despite the above qualifications one conclusion would seem to emerge from the discussion. It does appear that in any reasonably thorough program of economic growth there should be an analysis of the appropriate population policy. The most compelling reason for this would seem to be the very long lags which can be associated with changes in population levels. A change in birth rates now will not have an effect on the numbers in the work force or of reproductive age for fifteen or twenty years. An adjustment from a growing to a stable population could take thirty or more years. Anticipation of desirable population movements seems essential.

The only situation in which population growth would seem not to matter would be the sort of growth process portrayed by the growth model of Chapter 2 (provided there was also no preference expressed with respect to population density). This model required not only universal constant returns to scale, but also virtually unlimited resources. As it is most unlikely that these conditions hold, a population policy would seem inescapable for most economies. At the very least if it is felt that current population trends are desirable it is still necessary to justify this attitude.

\section{REFERENCES}

Barclay, G. W. 1958. Techniques of Population Analysis, Wiley, New York. Borrie, W. D. 1970. The Growth and Control of World Population, Weidenfeld and Nicolson, London.

Pitchford, J. D. 1973. Population in Economic Growth, North-Holland, Amsterdam.

Vousden, N. 1973. 'Basic Theoretical Issues of Resource Depletion', Journal of Economic Theory.

Wrigley, E. A. 1967. 'The Supply of Raw Materials in the Industrial Revolution', in Hartwell, R. M. (ed.), The Causes of the Industrial Revolution in England, Methuen, London. 


\section{Index}

Adelman, I., 32-3, 33n., 34

Age structure: effect on fertility, 3, 4, $31,82,86$; standard demographic model, 23, 24; effect of fertility and mortality on, 24; assumptions in optimum population model, 78,82

Australia: fertility, 30; effect of tariff, 53-4; estimates of optimum population, 65-8

Average family size, and the utility function, 47

Barkley, H., 67

Barnett, H. J. and Morse, C., 54-6

Becker, G., fertility theory, 29, 32

Belz, M. H., 66

Benham, F. C., 42, 66, 68

Berelson, B., $31 \mathrm{n}$.

Birth rate, 1, 2; age specific, standard demographic model, 24,25 ; and the demographic transition, 27, 28; crude, 31 ; Taiwan, 33

Birth subsidies and fertility, 73

Blaug, M., 35n.

Borrie, W. D., 27, 30, 73

Bowley, M., 35n.

Brigden Commission: Australian tariff, 53-4

Capital: depreciation and replacement, 8, 13, 69; optimum input combination, 13-14; conditions for optimum stock, 17-18; marginal product of and depreciation, 17; accumulation in growth models, 19 , 20, 21: and optimum population conditions, 42 ; returns to under optimum population conditions, 47 , 48; optimal conditions in many goods case, 50; corrected marginal product, 62 ; widening and deepening, 69; accumulation in optimum population model, 77

Carr-Saunders, A. M., 42, 66, 67

Children: as consumer durables, 29 ; as producer durables, 29

Closed population, standard demographic model, 23

Cocos Islands, fertility, 30

Collver, A., Speare, A., and Lui, P., 33-4

Competition, and returns to scale, 51

Conservation of resources, 63,65

Consumption: subsistence, 40; optimum population model, 79; age structure model, 84,85

Consumption per capita: welfare criterion, 12, 14; and average productivity of labour, 13; and output per capita at the optimum, 69 ; socially valued, 84

Death rate, 1,2

Dependents, age structure model, 83,85

Depreciation: and production function, 8 ; in a stationary economy, 13 ; and marginal product of capital, 17; per capita output and consumption, 69

Diminishing marginal utility, optimum population level and criteria, 45 
Discount rate: influence on utility function, 48, 49; and resource renewal, 64 ; age structure model, 85 , 87,88

Dynamics of optimal path, $72,73,88$

Economies, internal and external, 51

Economies of scale, and Ricardian system, 37, 38

Education, and fertility, 32, 33, 73

Environment, element of utility function, 47

Environmental management, 58, 59, $60,61,62$

Equilibrium, in Swan growth model, 21

Exhaustible resources, 57

Exponential trend, 18

Fertility: Lotka, 24; Becker, 29; effect of marriage rates, $30 ; \operatorname{Cocos}$ Islands, Hutterite, Australian, Indian, 30; and per capita income, $31,32,34$; age specific, 32; and trade cycle, 32, 34; Adelman, 32; and population density, 32, 33, 73; and education, 32, 33, 73; and urbanisation, 32; Taiwan, 33-4; and the stationary state, 37,38

Forster, B., 38

Full employment, in growth models, 19

Galbraith, V. and Thomas, D., 34

Growth models, 4; full employment, 19; Swan, 19; role of land in, 19, 22 ; output per head, 21

Growth rate: of a variable, 18 ; intrinsic and Lotka's propositions, 24-5, 31

Hajnal, J., 30n.

Hutterites, fertility, 30

Immigration, and population control, 73

Income: and fertility, 32, 33, 34; and mortality, 32, 33, 34, 73; and desired family size, 34

Income distribution: aspect of utility maximisation 47-8; at optimum population point, 61
Industrialisation: and the demographic transition, 27, 38; and mortality, 33

Inflation, control in a stationary economy, 70

Investment : in children, 29 ; optimum population model, $77,78,79,80$; age structure model, 85,88 ; replacement investment in a steady state, 88

Jevons, 92,93

Keyfitz, N., 27

Labour: average product, 9 ; marginal product, 9 ; conditions for optimum population, 15, 16, 17; Swan growth model, 19, 20, 21, 22; and total output criterion, 43 ; returns to under optimum population conditions 47, 48; optimal conditions in the many goods case, 50 ; unemployment in trading industries, 53 ; corrected marginal product, 62 ; employment in renewal activities, 63

Land: as input in production, 10-11; supply as a constraint in maximisation of output per head, $12,13,14$; role in growth models, 19,22 ; as a fixed factor, 34, 35, 36; as a renewable resource, 57; assumption of uniform quality, 60

Latin America, mortality and fertility, 1,2

Leisure, and the use of resources, 60

Linear trend, 18

Logistic curve: and population growth, 26; Australia's population growth, 66

Lotka, A. J., 24-5

Malthus, 10, 19, 26, 35, 55, 56

Marginal utility, characteristic of utility curve, 45

Marriage rate, and fertility, 30

Materials, and the production function, 10

Medical care, and mortality, 33

Mortality: age specific death rates, standard demographic model, 23, 24,25 ; effect on age structure, 24 ; patterns in Western economies, 27 ; 
Mortality (continued)

and the demographic transition, 27 , 28; infant, and fertility, 32; and income, 33, 34, 73; and medical care, 33 ; and industrialisation, 33; and the stationary state, 37,38

Mullet, H. A. and Wadham, S. M., 67

Neoclassical growth model, see Growth models

Net reproduction rate: United States, 3 ; defined, 24-5; and zero population growth, 25; and the subsistence wage, 28,29 ; and fertility comparison between countries, 31 ; in the stationary state, 38

Niehans, J., 35n, 37, 38

Optimum population and exhaustible resources, 90

Output, defined net of replacement, 13

Output per head: explained, 9; and per capita consumption, 13; and returns to scale, $13,14,15$; in growth model, 19; welfare criterion, $43,44,45,46$; and per capita consumption at the optimum, 69

Pearl, R. and Reed, L. J., 26, 66

Pitchford, J. D., 24n., 44n., 50n., 62n., $91 \mathrm{n}$.

Pollution, 59-60, 61 ; effect on output in the stationary state, 38 ; and resource use, 56 ; costs of control, 59

Population control: and people's preferences, 40; public good, 74; costs, $74,86,87$; public expenditure on, 74,75 ; optimum population model, $78,79,80,81,82$; age structure model, $84,86,87,88$

Population density: and fertility, 32 , 33,73 ; and the utility function, 45 , 46,47

Population growth assumption in optimum population model, 77,82

Population shifts, and utilisation of resources, 55

Production function: defined, 48; and technical progress, 8 ; and the fixed proportions assumption, 10 ; inputs, 10,11
Public good, 60; population control as, 74,75

Public intervention in resource exploitation, 64, 65

Renewal of resources, $57-65,69,70$

Rent, 35, 36, 60, 61

Resources: land, 34, 35, 36; substitution, 55-6; private ownership, 58; optimum exploitation rate, 89

Returns to scale: concept explained, 9-10; conditions for optimum population, 13, 14, 15, 17, 42; Swan growth model, 19; optimal conditions in the many goods case, 50 , 51 ; and competition, 51 ; in trading industries, 53; and use of resources, 60

Ricardo, 10, 19, 35-8, 55

Risk, aversion or preference under uncertainty, 93

Robinson, J. R., 19n.

Savings, role in Swan growth model, $19,20,21$

Solow, R. M., 19n.

Stationary state, $36,37,38,40$

Steady state, age structure model, 87 , 88

Stolper, W. F. and Samuelson, P. A., 53-4

Subsistence wage, $28,29,36,37,38$

Swan, T. W., growth model, 19-22

Taiwan, fertility study, 33-4

Tastes, and optimum population, 69

Tariff, and optimum population, 53, 54

Taylor, Griffith, 67

Technical progress: and the production function, 8; and the Ricardian system, 37 ; and Malthusian scarcity 55-6; and exhaustibility of resources, 57 ; and optimum population, 68 ; uncertainty of, 93

Terms of trade: defined, 52; and optimum population, $52,53,54,94$

Total output criterion, 43,44

Trade, closed economy assumption, 11

Trade cycle studies of fertility, 32, 34

Tucker, G. S. L., 35n. 
Underdeveloped countries, and demographic transition, 28

Urbanisation: and demographic transition, 27, 28; and fertility, 32, 33

Utility function, 44-9

Vousden, N., 89n.

Wage: subsistence, $28,29,36,37,38$; real and Ricardian theory, 28 ; and the employment of land in the
Ricardian system, 36; real and the tariff, 53, 54

Welfare, criteria, 12; maximisation and optimum population, 41

Work force: assumption of equality with population, 10 ; in age structure model, 83

World population, 1-3

Wrigley, E. A., 92, 93

Zero population growth and the net reproduction rate, 25 
John Pitchford's chief interests are in the fields of population economics and inflation and he is the author of $A$ Study of Cost and Demand Inflation (1963) and Population and Economic Growth (1974), a more technical approach to the subject of this book. He has been Professor of Economics at the Australian National University since 1965.

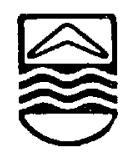

Designed by Arthur Stokes

Text set in 10/12 Monotype Times Roman and printed on $85 \mathrm{gsm}$ Burnie English Finish by John Sands Pty Ltd, Artarmon, New South Wales 
John Pitchford's chief interests are in the fields of population economics and inflation and he is the author of A Study of Cost and Demand Inflation (1963) and Population and Economic Growth (1974), a more technical approach to the subject of this book. $\mathrm{He}$ has been Professor of Economics at the Australian National University since 1965 . 